\title{
LA OBLIGACIÓN DE SEGURIDAD EN LA SUBCONTRATACIÓN LABORAL: PREVISIBILIDAD DEL HECHO Y DEL DAÑO
}

\author{
THE OUTSOURCING SAFETY LABOR OBLIGATION : DAMAGE \\ PREDICTABILITY AND DAMAGE DONE
}

MARCELO BARRIENTOS ZAMORANO***

RESU MEN: El sistema actual de subcontratación, vigente a partir de la reforma impulsada en el año 2007, ha generado una nueva forma de entender la obligación de seguridad en el derecho del trabajo y la responsabilidad civil. De todas las áreas que fueron reformadas, conviene mirar especialmente el cambio de la obligación de seguridad comprendida en la relación laboral y su aplicación en la jurisprudencia en relación al problema de previsibilidad del hecho y del daño; específicamente en la que dice relación con respecto a trabajadores subcontratados y los daños que estos pudieran sufrir en el desempeño de sus labores.

Palabras dave subcontratación; obligación de seguridad; daños; previsibilidad.

ABSTRACT: The current system of outsourcing, effective reform driven in 2007, has generated a new understanding of safety requirement in the labor law and tort law. Of all the areas that were renovated, it should look especially changing the security requirement included in the employment relationship, specially about the main difference between damage predictability and damage done, and its application in case law that says specifically in the relationship to contract workers and the damage that they could suffer in the performance of their duties.

Key words outsourcing; safety obligations; damage; predictability.

\section{INTRODUCCIÓN}

La reparación del daño en cualquier juicio de responsabilidad civil está encaminada a la indemnización del perjuicio en términos tales de colocar a la víctima en el estado anterior a la producción de daño. La cosa pedida es el daño, el objetivo es la "restitutio in integrum". En la subcontratación tales contornos se difuminan más, si cabe. La triangulación de la figura "Empresa Principal-Contratista-Trabajador subcontratado" genera dificultades

\footnotetext{
* Profesor de D erecho Civil, Pontificia Universidad C atólica de Chile. Email: mhbz@uc.cl D octor en D erecho con mención "D octor Europeus", U niversidad de Salamanca, España. M agíster en Derecho de la Empresa, Pontificia U niversi dad C atólica de C hile. Abogado.

** El autor quiere agradecer la colaboración prestada en la investigación por el ayudante del Diplomado en Nuevas Tendencias en Contratos y Daños de la Facultad de D erecho de la Pontificia Universidad Católica de Chile, versión IV, año 2010, don Sebastián H errera Larraín. Asimismo, agradezco las valiosas correcciones de los árbitros de la Revista Chilena de D erecho para este artículo, a quienes por supuesto no conozco por su calidad de árbitros ciegos. Ellos generosamente aprobaron su contenido, enriqueciéndolo con sus agudos puntos de vista en sus respectivos fallos, puntos que en su gran mayoría acogí. M uchas gracias a todos.
} 
en los resarcimientos de los perjuicios sufridos por los trabajadores en sus labores y se hace ardua, por lo tanto, la determinación del quantum indemnizatorio.

Este artículo busca separar las causalidades del hecho y del daño en una figura tan necesaria como equívoca: la subcontratación laboral.

Los elementos a considerar ante un accidente del trabajo en régimen de subcontratación son muchos, aunque desde ya y al igual que $\mathrm{M}$ ariano Alonso fijamos una posición. Creemos que existe hoy por hoy en estas materias un auténtico "mito de la reparación integral". Esta era "una pretensión inasequible de los juristas romanos (D . 9,2, 51, 2; Gayo, 3, 122), que requi ere, solo para aproximarse, un juicio certero de equidad (a veces más apto para reducir, que para lograr la plenitud indemnizatoria)" 1.

En materias como la que surge de accidentes del trabajo en la subcontratación se agrava el "mito de la reparación integral" a partir de la apreciación, según se trate, de una responsabilidad por riesgo o por culpa generalmente levísima. Así lo fue, por lo menos, en los términos del ahora derogado artículo 64 del Código del Trabajo². Ese viejo esquema ha

\footnotetext{
${ }^{1}$ Alonso (2010) p. 24. En cualquier caso, prueba de que la reparación integral no es más que un mito que es conveniente ir desterrando es la majadera realidad. El lucro cesante es prueba patente de ello en materia de subcontratación, es claro que lo que se ha dejado de percibir por el trabajador debe ser indemnizado, pero respecto de futuras rentas que se hubieran percibido de no mediar el daño sufrido, la reticencia de la jurisprudencia a indemnizar pareciera ser la regla general. Se pueden citar varios fallos en tal sentido: "En nuestro sistema laboral, que rige las relaciones del sector privado, no existe propiedad en el empleo y nada permite asegurar que las condiciones de remuneraci ones que tenía un trabajador puedan permanecer en el tiempo, lo que le hace perder el carácter de cierto que debe tener el daño para llegar a ser indemnizado. Es cierto que el lucro cesante dice relación con eventos futuros, cuestión que excluye la posibilidad de certeza absoluta, pero, sin embargo, nada obsta para requerir una razonable certeza en la producción del daño, lo que aquí se echa de menos, porque no hay antecedentes que permitan de forma suficiente concluir en tal sentido", Salgado con Sociedad. (2010). En otro fallo se señala: "Al no saberse con exactitud si el trabajador accidentado ha quedado imposibilitado para todo tipo de labor futura, no puede darse lugar a la indemnización por lucro cesante deducida, ya que el cál culo de sueldos es una mera espe culación, más aún si dicho cálculo omi te los subsidios que ha recibi do durante las licencias médicas". M artínez con Sociedad. (2010). "Q ue del mérito de los antecedentes all egados en autos, no ha logrado establecerse la existencia del perjuicio patrimonial que se demanda por tal concepto, desde que el vivir de una persona por determinados años y las eventualidades de trabajos, constituyen eventos imposi bles de determinar e impiden establecer en forma concreta, ci erta y precisa la pérdida patrimonial experimentada por el actor, por lo que deberá desestimarse la indemnización por este capítulo", G onzález con M arineer. (2010). "Q ue, respecto del recurso de nulidad intentado por el demandante, fundado en la causal contenida en el artículo 477 del Código del Trabajo, por infracción de ley referida al artículo 69 letra b) de la ley 16.744, como ya se ha explicado, esta se habría cometido al rechazar la sentencia la indemnización solicitada por concepto de lucro cesante, ascendente a la suma de \$146.082.301, petición fundada en que el actor vio disminuida su capacidad laboral en un $90 \%$, representada por los emolumentos que dejará de percibir con ocasión del accidente. Q ue dicho rechazo se ha basado en que no es posible indemnizar un daño sobre la base de especulaciones, como lo ha señalado la demandada Conafe, habida consideración a la circunstancia que la pérdida de la capacidad laboral del trabajador ha sido suplida con la pensión, que se acreditó recibe por los entes de seguridad social respectiva", Ramos con A segim. (2010) Sobre este último fallo en particular, Schiele (2011) pp. 37-58, y en general sobre lucro cesante en estas materias, CaPrILE (2011) pp. 107 a 113.

2 El hoy derogado artículo 64 del Código del trabajo, disponía lo siguiente: "El dueño de la obra, empresa 0 faena será subsidiariamente responsable de las obligaciones laborales y previsionales que afecten a los contratistas en favor de los trabajadores de estos. También responderá de igual es obligaciones que afecten a los subcontratistas, cuando no pudiere hacerse efectiva la responsabilidad a que se refiere el inciso siguiente. (Inciso $2^{\circ}$ ) En los mismos términos, el contratista será subsi diariamente responsable de obligaciones que afecten a sus subcontratistas, en favor de los trabajadores de estos. (Inciso 3ㅇ) El trabajador, al entablar la demanda en contra de su empleador directo, podrá también demandar subsidiariamente a todos aquellos que puedan responder en tal calidad de sus derechos. (Inciso
} 
quedado atrás, y se ha consagrado legalmente uno nuevo que pondera la obligación de seguridad dinámica involucrada en la relación de subcontratación. Lo que tiende a empañar aun más el panorama de la reparación integral del daño en estas materias.

Conviene detenerse y examinar este nuevo esquema de obligación, sobre todo a la luz de la jurisprudencia reciente.

La nueva reglamentación no pone en duda un aspecto importante y es que hay siempre, y en cualquier esquema de responsabilidad, una enorme diferencia entre estar obligado y ser responsable3. Así, el incumplimiento de una obligación de seguridad que no acarree daños, simplemente, no dará lugar a indemnizaciones de perjuicios en un juicio de responsabilidad. No hay daño que indemnizar. La obligación de responder no es el resultado de la existencia de una obligación de seguridad en el trabajo a secas, sino que tiene lugar ex novo, por el hecho del incumplimiento del tal obligación que causa daño al trabajador.

La responsabilidad civil del empresario (Ilamado así en la legislación española y que en la chilena equivale al contratista) significaría, por tanto, la asunción por parte de dicho sujeto de las consecuencias lesivas derivadas del incumplimiento de sus deberes de seguridad y salud en el trabaj $0^{4}$. Aunque en esto se ha de ir con mucho cuidado porque ni todos los daños sufridos por los trabajadores como consecuencia de la realización de los riesgos laborales encuentran su explicación en un comportamiento antijurídico del contratista, ni estos últimos daños son los únicos que el ordenamiento jurídico va a atribuir jurídicamente a la empresa principal o al contratista5.

\section{MARCO NORMATIVO BÁSICO DE LA OBLIGACIÓN DE SEGURIDAD EN LOS PROCESOS DE SUBCONTRATACIÓN}

El inicio del nuevo escenario en materia de subcontratación y seguridad está refrendado por el artículo 183 E del Código del trabajo:"la empresa principal deberá adoptar las medidas necesarias para proteger eficazmente la vida y salud de todos los trabajadores que laboran en su obra, empresa o faena, cualquiera sea su dependencia, en conformidad a lo dis puesto en el artículo 66 bis de la ley $\mathrm{N} \cong 16.744$ y el artículo 3이 del decreto supremo $\mathrm{N} \cong$ 594, de 1999, del M inisterio de Salud". Recordemos que con anterioridad ya el Reglamento sobre

4ํ) En los casos de construcción de edificios por un precio único prefijado, no procederán estas responsabilidades subsidiarias cuando el que encargue la obra sea una persona natural". Los paréntesis son nuestros. Sobre el tema en perspectiva histórica: Gumucio et al. (2011) pp. 81 y ss.; ZelayA (2003) pp. 43-44; ZelaYA (2006) pp. 1-29; Gumucio (1999) pp. 59 y sS.; Gumucio (2000) pp. 91-93; PeÑa et al. (2004) pp. 152-162; Walker (2003) pp. 424-429; Ugarte et al. (2007) p. 35; Diez (2008) p. 165; Humeres (2009) pp. 286 y siguientes; 12; GAmonal et al. (2010) pp. 53 y siguientes; Lizama et al. (2009) pp. 1 y siguientes.

${ }^{3}$ Barros (2006) pp. 721-752.

${ }^{4}$ Gutiérrez-Solar (2004) p. 21.

5 En este sentido, Gamillscheg. et al. (1965): "für die Fürsorgepflicht kein Anwendungsbereich mehr da ist, wennn der Schaden ohnehin in den Gefahrbereich des AG fallt", defienden que la totalidad de los daños que puede sufrir el trabajador no encuentran su fundamento resarcitorio en el deber del empresario de protección, en concreto en su transgresión o comportamiento culposo. No cabe duda, el campo de riesgos que el empresario debe soportar es más extenso que el campo de protección que el deber de seguridad del empresario debe garantizar. 
Condiciones Sanitarias y Ambientales en los Lugares de Trabajo (DS N 594) había establecido, en su artículo $3^{\circ}$, que las empresas deben mantener correctamente las condiciones sanitarias y ambientales en sus lugares de trabajo, a fin de proteger la vida y salud de los trabajadores que en ella se desempeñan, sean dependientes directos suyos o de terceros contratistas que realicen actividades para ella. Estimamos que la nueva reglamentación, refuerza, qué duda cabe, estas obligaciones en la forma que pasamos a explicar.

En consecuencia, y de acuerdo a una jurisprudencia reciente existe una estipulación expresa con "virtud, actividad, fuerza y poder" 6 para obrar respecto del deber de una parte de mantener incólume, sin daño, a la parte más débil en este tipo de relaciones laborales ${ }^{7}$. D eriva de la misma naturaleza del contrato y produce, por tanto, sus efectos con independencia de que sea o no expresamente asumida en el momento de la celebración la convención que le da origen entre la empresa principal y su contratista o subcontratista8. Reconoce, más bien, su fuente en la ley e influye o incide en el contrato, más allá de la voluntad de los contrayentes en virtud del orden público de protección?.

El marco que complementa el artículo $183 \mathrm{E}$ es el nuevo artículo 66 bis de la Ley $\mathrm{N}$ o 16.744, inciso $1^{\circ}$, el que señala que: "Los empleadores que contraten 0 subcontraten con otros la realización de una obra, faena o servicios propios de su giro, deberán vigilar el cumplimiento por parte de dichos contratistas o subcontratistas de la normativa relativa a higi ene y seguridad". Es interesante esta disposición porque agrega que debe haber un sistema de gestión de la seguridad y salud en el trabajo para todos los trabajadores involucrados, "cualquiera que sea su dependencia, cuando en su conjunto agrupen a más de 50 trabajadores". Al tratarse de una materia de orden público no es posible una convención de exclusión de responsabilidad para ninguna de las partes de la relación jurídica.

El empresario principal, a través del contratista o subcontratista, según sea el caso, están obligados por ley a conocer y dar a conocer las reglas de seguridad que rodean la actividad del trabajador y a aplicarlas, asumiéndose el criterio de que quien lleva adelante una empresa que compromete en su actividad obligaciones de seguridad, se presume iuris

\footnotetext{
${ }^{6}$ La sentencia en su contexto señala: "8ㅇ) Q ue no está de más consignar que atendido que se trata de una responsabilidad contractual, la responsabilidad resulta de no haberse comportado la empresa principal como lo haría un hombre juicioso en la administración de sus negocios importantes; ello, debido a que la ley exige de su parte no una mediana diligencia, sino una extrema diligencia o cuidado. Se advierte, en este sentido, que la ley obliga a adoptar las medidas necesarias (todas las que lo sean) para proteger eficazmente la vida y la salud de todos los trabajadores que laboran en su obra, empresa o faena, cualquiera sea su dependencia (Art. 183 E del Código del Trabajo). No se conforma la ley con decir que tiendan a proteger, exige que sean para proteger. Huelga decir, que eficazmente significa en el lenguaje común en que está tomado, con virtud, actividad, fuerza y poder para obrar". Germán Silva Valencia con S Y R Tecnología y Servicios Integrales (2010).

${ }^{7} \mathrm{No}$ en vano los propios hermanos M azeaud señalaban hace varios lustros que: "El contrato de trabajo, sus condiciones, la higiene y la seguridad de los trabajadores deben constituir el objeto de una reglamentación particularmente protectora". MAZEAUD (1959) et al. pp. 24.

${ }^{8}$ Melis et al. (2009) pp. 197 y siguientes. Albornoz et al. (2008) pp. 149 y 168 y siguientes.

9 Sobre estos extremos, como señala una autora, “(sic) El reconocimiento a favor de los trabajadores de un específico derecho en materia de seguridad y salud en el trabajo significa que el legislador otorga una relevancia y tutela específicas al interés privado y extrapatrimonial propio del trabajador en disfrutar de unas condiciones de trabajo seguras para su vida, su integridad y su salud, al margen e independientemente del interés general y público que al mismo tiempo concurre en la materia de la seguridad y salud en el trabajo". Martín (2006) p. 408.
} 
et de iure, que conoce las reglas de seguridad que rigen tal actividad. Al fin y al cabo, es un profesional de su actividad.

En consecuencia, "cuando se trata de prestaciones técnicas, el contenido de lo debido, el facere diligente, se convierte en la observancia de las reglas técnicas del arte, profesión y oficio de que se trate" 10.

En su inciso segundo el Artículo 66 bis de la ley 16.744 exige nuevos elementos propios de la obligación de seguridad en esta especial forma de relación laboral: "Para la implementación de este sistema de gestión, la empresa principal deberá confeccionar un reglamento especial para empresas contratistas y subcontratistas, en el que se establezca como mínimo las acciones de coordinación entre los distintos empleadores de las actividades preventivas, a fin de garantizar a todos los trabajadores condiciones de higiene y seguridad adecuadas. Asimismo, se contemplarán en dicho reglamento los mecanismos para verificar su cumplimiento por parte de la empresa mandante y las sanciones aplicables". Es imposible en este punto entender que los principios de responsabilidad obedecen a uno solo en todas las hipótesis, como si no se pudieran completar o dinamizar con más normas que dependan de su naturaleza y contexto11. Finalmente, el propio inciso $3^{\circ}$ artículo 66 bis de la Ley $N^{\circ} 16.744$ termina señalando que: "Asimismo, corresponderá al mandante, velar por la constitución y funcionamiento de un Comité Paritario de Higiene y Seguridad y un Departamento de Prevención de Riesgos para tales faenas, aplicándose a su respecto para calcular el número de trabajadores exigidos por los incisos primero y cuarto, del artículo 66, respectivamente, la totalidad de los trabajadores que prestan servicios en un mismo lugar de trabajo, cualquiera sea su dependencia. Los requisitos para la constitución y funcionamiento de los mismos serán determinados por el reglamento que dictará el M inisterio del Trabajo y Previsión Social".

Sin perjuicio de lo anterior, no debe olvidarse que estas normas no son las únicas que han modificado la obligación de seguridad en el régimen de subcontratación, y que se unen a otras que complementan, refuerzan y llenan su contenido. Es por ello que cualquier análisis que se realice deberá considerar forzosamente las normas reglamentarias producto de la reforma al régimen de subcontratación. Así, no debe obviarse el D ecreto Supremo No 76, del M inisterio del Trabajo y Previsión Social (publicado en el Diario 0 ficial de 18 de enero de 2007), que aprobó el "Reglamento para la aplicación del artículo 66 bis de la Ley $N^{\circ} 16.744$ sobre la gestión de la seguridad y salud en el trabajo en obras, faenas 0 servicios que indica"12.

\footnotetext{
${ }^{10}$ JoRDANO (1987) pp. 172 y 460.

${ }^{11}$ Cabe recordar aquí aquello que lúcidamente señalaba Larenz: "No hay un único princi pio de responsabilidad por daños, sino varios, y cada uno de ellos tiene su propio campo de aplicación. Es común a todos la idea de una justa compensación del daño o de un justo reparto de determinados riesgos de daños" LaRenz (1985) p. 120. En consecuencia, el que a todos ellos sea común el reparto de determinados riesgos y daños, no implica que en todo ellos sea lo único que hay que tener en cuenta.

12 Para un lúcido análisis, Diez (2008) pp. 173 y siguientes; Lizama et al. (2009), pp. 50 y siguientes.
} 


\section{LA OBLIGACIÓN DE SEGURIDAD EN LA SUBCONTRATACIÓN SUPONE UNA NUEVA OBLIGACIÓN PARA LA EMPRESA PRINCIPAL}

Estimamos que estamos frente a una nueva configuración de la obligación de se guridad, un verdadero sistema de gestión del riesgo en las faenas laborales relacionadas a la subcontratación ${ }^{13}$. La formulación actual ya no se fija en el sistema de prestaciones de seguridad social que tenía lugar frente a un "accidente del trabajo" o "enfermedad profesional" cuando este ya ha ocurrido; ahora va más allá, y el énfasis está también puesto en el momento anterior al hecho que causa el daño: en su previsibilidad.

Las obligaciones de seguridad e higiene, que están en la base de un incumplimiento que provoca un accidente o enfermedad en un trabajador, son bastante más estrictas después de la reforma de 2007, y traen aparejada una diligencia también extremada, por la entidad de los bienes jurídicos que se tratan de proteger: vida y salud de los trabajadores. Así lo han afirmado nuestros tribunales "(sic) El artículo 184 del Código del Trabajo contiene sin duda una obligación de seguridad que debe cumplir el empleador hacia sus trabajadores dependientes, lo que significa que está obligado a velar por su seguridad e integridad a todo evento y es, en consecuencia, el empleador quien debe probar el cumplimiento de dicho deber, máxime que en este caso, en el ámbito de la responsabilidad contractual, la culpa se presume, acorde a lo previsto en el inciso tercero del artículo 1547 del Código Civil" 14.

Tal y como ocurre en otros ordenamientos desde hace bastante tiempo, se encuentra obligado a adoptar todas las medidas de prevención, aun las no previstas reglamentariamente, siempre que no resulten imposibles. Las posibilidades o no de su aplicación, marcan, aunque no pocas veces de forma imprecisa, los límites propios de la obligación de seguridad $^{15}$. N o es de extrañar, entonces, que la normativa de seguridad e higiene se asemeje a una responsabilidad objetiva o en grado de culpa levísima al menos. La propia noción de culpa pareciera quedar superada frente a este tipo de accidentes del trabajo, ella aparece como implícita en la conducta de quien debiendo no cumple con su obligación. La diligencia obligada y su inobservancia conllevan, en gran parte de los casos, una negligencia en el cumplimiento de la prestación. Pese a lo anterior, al contratista no puede exigírsele que garantice que el accidente laboral no se va a producir, si así fuera estaríamos exigiendo un comportamiento más allá de lo razonable, una auténtica contradicción jurídica. Lo que sí puede pedírsele es que lo prevea en el hecho que potencialmente lo causaría y en la mitigación de los daños una vez que se produzca.

Consecuencias del cambio legislativo experimentado en el país se pueden anotar varias. Tal vez la principal resida en que se abandona aquella disciplina legal en la que solo existía la posibilidad de que surgiera responsabilidad civil "cuando el accidente o enfermedad se deba a culpa o dolo de la entidad empleadora o de un tercero".

\footnotetext{
13 "Es la normativa de la Ley $\mathrm{N} 020.123$, la que introduce en el ámbito de las relaciones laborales (entre empresa principal y contratista), el concepto de sistemas de gestión de seguridad y salud en los ambientes de trabajo". Cifuentes (2011) p. 19.

14 Salgado con Sociedad (2010).

15 Fernández (1995) pp. 16 y 244.
} 
Variada interpretación tiene la posibilidad de que las demás personas a quienes el accidente 0 enfermedad cause daño, puedan reclamar al empleador 0 terceros responsables del accidente, también las otras indemnizaciones a que tengan derecho, con arreglo a las prescripciones del derecho común, incluso el daño moral. No queremos señalar con esto que esta norma no se aplique, lo que decimos es que la obligación de seguridad en estos casos ha salido fortalecida y es más exigente.

Esta severidad en la nueva ley coloca una carga rigurosa de prueba al empleador 0 contratista, al mandante hoy llamado empresa principal, en el esquema del Código del Trabajo. No es una culpa derivada, en segundo plano o a consecuencia de otra, sino una responsabilidad por culpa propia o "directa"16.

El actual artículo 183 E introducido al Código del Trabajo por la Ley ${ }^{\circ} 20.123$, afectó a la responsabilidad de la empresa principal. En efecto, como señalábamos, lo que existe hoy es una "obligación directa" de la empresa principal en orden a adoptar las medidas necesarias para proteger eficazmente la vida y salud de todos los trabajadores que laboran en su obra, empresa o faena, cualquiera sea su dependencia, en conformidad a lo dispuesto en el artículo 66 bis de la ley $N$ N 16.744 y el artículo 3 을 del decreto supremo $\mathrm{N}$ 594, de 1999, del Ministerio de Salud ${ }^{17}$. Estas medidas, como veremos, generan también los controles necesarios para verificar el estricto cumplimiento de las condiciones de seguridad e higiene que la ley manda observar ${ }^{18}$.

Esto es así, porque la responsabilidad subsidiaria del dueño de la obra, empresa 0 faena (empresa principal), en cuanto a estas obligaciones de seguridad, pasa a segundo plano en caso de producirse un accidente. Si hay accidente, todo pareciera indicar que se debe responder, tal y como señala la jurisprudencia reciente ${ }^{19}$. Ahora bien, si se adoptan todas las medidas, no debiera concurrir responsabilidad de la empresa principal, aunque si

16 Corral (2011) p. 61; Lizama et al. (2009) pp. 50 y siguientes.

17 Ugarte (2006) p. 20.

18 Esfuerzos, por cierto, consistentes con la de otras legislaciones como por ejemplo la "Estrategia Europea de Seguridad y Salud en el Trabajo 2007-2012", que tiene como objetivo reducir en un 25 \% la incidencia de accidentes en el trabajo, cuyos progresos se evalúan en la Unión poniendo de relieve que el papel de la seguridad y la salud es fundamental para incrementar la competitividad de las empresas, y las mejoras en el ámbito de la prevención reducen costos, accidentes y enfermedades profesionales, al tiempo que conllevan una mayor motivación de los trabajadores y trabajadoras. Se ha llamado la atención sobre la necesidad de que en este proceso se impliquen no solo los empresarios, sino también los trabajadores. Carrancho (2010) p. 225.

${ }^{19}$ Como señala un fallo reciente: "C orresponde acoger el recurso de apelación interpuesto por el actor y declarar la responsabilidad de las demandadas principal y subsidiaria por el accidente sufrido por el recurrente, puesto que ha sido fehacientemente acreditado que ambas no cumplieron con la obligación de seguridad contenida en el artículo 184 del Códi go del Trabajo, ya que no se encontraban supervisando las faenas en el momento de producirse el accidente". M ás delante agrega: "Establecida la responsabilidad de la empresa contratista, responde de manera sol idaria qui en encargó la ejecución de la obra, sin que a su respecto sea necesario establecer elementos subjetivos de imputabilidad, como son el dolo o la culpa, sea en el accidente como en la resolución del respectivo contrato". "El artículo 183 B del Código del Trabajo es de carácter amplio en cuanto a su contenido, ya que al referirse a las obligaciones laborales no excluye ni alude a ninguna en especial, quedando comprendidas todas aquellas obligaciones que tengan su origen en una relación laboral. Por lo que la subsidiariedad no tiene limitación en cuanto a la naturaleza y origen de la obligación, y por lo mismo no está restringida solo a las remuneraciones, sino también a los beneficios y retribuciones o indemnizaciones". G onzález Corrotea, Julio c/ M arineer Zona Franca S.A. y otra (2010). 
el daño se produce pareciera difícil, a la luz de los precedentes judiciales, eludir la responsabilidad directa de la empresa principal.

\section{SOBRE LA DEUDA O CRÉDITO DE SEGURIDAD PROPIA DEL RÉGIMEN DE SUBCONTRATACIÓN}

Existe una obligación de seguridad legal, tanto para la empresa contratista o subcontratista, como para la empresa principal y los trabajadores, según sea el caso. Estos últimos quedaron facultados para reclamar protección de su vida y salud en el lugar de trabajo20.

Conviene en este punto reparar en la forma de interpretar esta obligación de seguridad impuesta por la ley 20.123 en nuestro país, que modificó el artículo 183 del Código del Trabajo.

En la responsabilidad contractual el comportamiento ilícito del contratista es al mismo tiempo la violación de un deber contractual de protección, que llevado a una hipótesis extracontractual, que no es el caso de la nueva reglamentación de subcontratación y suministro, sería un atentado contra el principio "alterum non laedere". Es diferente incumplir un contrato a cometer un ilícito civil fuera de él21.

A parecen estas ideas sostenidas por la propia jurisprudencia reciente, así la Corte de Apelaciones de C hillán ha señalado que: "atendido el mérito de los antecedentes y del tenor de la demanda deducida, consta que la responsabilidad de la empresa principal es de naturale za contractual, en atención a lo dispuesto en los artículos 183 B, 183 E y 184 del Código del Trabajo. En la especie, el demandante está ligado en virtud de un contrato de trabajo con la demandada, Carnes Ñ uble S.A., a virtud del amparo del régimen de subcontratación. Q ue, como corolario de lo expuesto, la demandada Carnes Ñ uble S.A., no puede ser considerada en estos autos como un tercero ajeno y sin vinculación jurídica alguna, como tampoco puede soste-

\footnotetext{
20 Esto es especial mente importante en sectores productivos relevantes para el país como la minería, nos referimos "al programa de erradicación de la ślicosis. La Ley exige que a los trabajadores sometidos al riesgo de la neumoconi osis se les efectúen exámenes semestrales. En este ámbito y en el marco del programa Global de erradicación de la silicosis en el mundo al año 2030, promocionado por la O M S y la OIT, el M IN SAL y el M inisterio del Trabajo, M IN TRAB, definieron una estrategia que guía el actuar de los responsables en la tarea de erradicar la silicosis, entendida como un problema de salud ocupacional. Los objetivos de esa estrategia son: di sminuir y control ar la exposición al sílice en los lugares de trabajo; disminuir la incidencia y prevalencia de silicosis, mejorar el diagnóstico oportuno y el control de salud de los trabajadores con sili cosis, aś como el acceso a las prestaciones pecuniarias e implementar un programa de (sic) social; fortalecer el sistema de información de silicosis y de exposición a ślice y de sarrollar un sistema de vigilancia, e implementar, desarrollar y evaluar un plan, a través de mecanismos tripartitos, que fortalezcan la partici pación de los trabajadores y el trabajo intersectorial". Cifuentes (2011) p. 20.

${ }^{21}$ Es bueno aclarar que la nueva Ley de modernización del derecho de obligaciones del Código civil alemán de 26 de noviembre de 2001 (G esetz zur M odernisierung des Schuldrechts), que entró en vigor el 1 de enero de 2002 , recoge expresamente esta doctrina en el $\S 241.2$ del BGB, pues establece que el deudor y el acreedor, además de estar vinculados por el deber primario de prestación (Leistungspllicht), lo están también por los Ilamados deberes de protección, disponiendo a su vez el § 282 del BG B una indemnización por la violación de estos deberes de protección, o como son llamados por el derecho francés, deberes de seguridad. Estos son propios de un marco contractual. En este sentido, Lamarca (2002) pp. 3 y siguientes.
} 
nerse que a su respecto rigen las normas legales relativas a la responsabilidad extracontractual de los artículos 2.314 y siguientes del Código Civil" 22.

La naturaleza contractual del derecho de los trabajadores subcontratados a la seguridad y salud en el trabajo no resulta, por lo anteriormente apuntado, incompatible con el hecho de que el deber de seguridad impuesto legislativamente al contratista haya sido configurado al mismo tiempo como un deber cuyo cumplimiento está orientado a la satisfacción de un interés general y público23.

No queda la menor duda que los deberes de protección del contratista en materia de seguridad y salud en el trabajo se pueden asimilar al principio de no dañar a otro, pero ello no es relevante en materia contractual, ya que el cumplimiento del deber general se expresa en esta materia por la observancia de las cláusulas del contrato. Así, el deber de seguridad que surge de la ley de subcontratación, y la naturaleza propia del contrato de trabajo, se fija y anida enteramente en el sinalagma contractual laboral traspasado por el deber de protección propio, de orden público, de la relación laboral24.

Se puede decir que la nueva normativa hace a la empresa principal y a la contratista un "deudor de seguridad" 25. El deber general de prevención de daños de la empresa es más exigente en la actualidad y, por la forma en que se ha aplicado por los tribunales, es verdaderamente un crédito a favor del trabajador subcontratado26.

Si el costo en seguridad laboral es al menos 4 veces menor que el costo de los accidentes producto del trabajo, entonces no podemos coincidir con quienes sostienen que el deber de seguridad interpretado de manera muy estricta equivalga a atentar contra la seguridad jurídica que consagra el artículo $19 \mathrm{~N} \cong 26$ de la Constitución Política, y mucho menos que atente contra el legítimo ejercicio del derecho a desarrollar cualquier actividad económica, sino más bien todo lo contrario, ya que consentir la siniestralidad es lo que conculca estos derechos constitucionales ${ }^{27}$.

Los deberes de seguridad o protección no aparecen simplemente como obligaciones de medios o actividad o de aquellos a que hace alusión el artículo 4401547 inciso tercero del Código Civil, son una regla de negocios exigente para un contratista, incluso el de una PYMES, ya que el no respetarlos es ineficiente por su alto costo público y privado. Cabe recordar que el déficit previsional chileno por pensiones asistenciales por invalidez, a con-

\footnotetext{
22 Saavedra con Carnes (2011).

${ }^{23}$ En este mismo sentido, Smuraglia (1967) p. 58; Simi, V. (1969), pp. 4 y 6; y Montuschi, L., (1989) p. 53; Martín (2006) pp. 21.

24 D e esta forma se expresa en una sentencia reciente:“(... ) cabe señalar que el artículo 183-B del Código del Trabajo, incorporado a dicho cuerpo normativo por Ley $\mathrm{N}^{\circ} 20.123$, contiene en su inciso cuarto una norma especial aplicable al régimen de subcontratación - la que por tener además carácter procesal rige in actum- en la cual se establece que "el trabajador al entablar la demanda en contra de su empleador directo, podrá hacerlo en contra de todos aquellos que puedan responder de sus derechos, en conformidad a las normas de este Párrafo". Elgueta con Servicios (2010).

$25 \mathrm{~N}$ omenclatura usada en otros ordenamientos, Montoya (2004) p. 307.

26 "Según información de la OIT los países que tienen menos accidentes fatales son los más competitivos. Este organismo estimó el costo de los accidentes y enfermedades relacionadas con el trabajo en un $4 \%$ del PIB mundial, y un $10 \%$ en América Latina. Los expertos indican que el costo en seguridad es al menos 4 veces menor que el costo de los accidentes". Sobre el tema: VARGAS (2011) pp. 72 y siguientes.

${ }^{27}$ En sentido diverso, Baraona (2011) p. 158 y Sierra (2011) p. 44 quien expresamente le sigue.
} 
secuencia de incumplimientos de obligación de seguridad, promedia el 4,8\% del PIB en el período 1999-201028.

Se trata la seguridad laboral de un deber genérico que tiene una función preventiva. Está diseñado, conforme a las reglas vigentes, a evitar los riesgos, a ponderar aquellos que no se puedan evitar, estimando aquellos posibles de ocurrencia, empleándose en todo esto una diligencia ordinaria que alcanza también a los trabajadores y que evita costos mayores.

Este plan de prevención general de seguridad no se agotará con su diseño, fue concebido para estar permanentemente en revisión ${ }^{29}$. En ello resulta prioritario evaluar las capacidades profesionales de los trabajadores en materia de seguridad y salud que se desempeñarán en las faenas. El deber de seguridad tiene por objeto que se adopten las medidas necesarias a fin de garantizar que solo los trabajadores que hayan recibido información suficiente y adecuada puedan acceder a las zonas de riesgo grave y específico.

La deuda de seguridad de las empresas, con la nueva reglamentación, tiende a la profesionalización de los medios de protección, lo que alcanza a la vigilancia del efectivo cumplimiento de tales medidas en la práctica. Esto, en el escenario de la subcontratación, supone dar o impartir órdenes directas a la empresa contratista por parte de la empresa principal. En caso alguno podrá la empresa principal dar órdenes directas a los empleados subcontratados porque ellos no son sus subordinados.

Es claro que el ejercicio de facultades disciplinarias, en esos casos, solo puede ejercerse por la empresa contratista sobre sus trabajadores ${ }^{30}$. Lo que debe hacer el supervisor de la empresa principal, se relaciona con supervigilar el trabajo convenido por los trabajadores del contratista, impartir las órdenes pertinentes y efectuar los correspondientes controles al supervisor del contratista, actividades que, en su calidad de representante de este, deberá realizar de manera periódica y permanente. No podrá jamás dar órdenes directas a los empleados subcontratados, ya que ello es indiciario de subordinación y dependencia. A hora bien, la sola existencia de un supervisor no debiera hacer entender per se la existencia de un régimen de subcontratación 31.

La empresa principal, a través de la contratista, debiera, en aplicación del deber de seguridad, impedir, si del caso fuera, que desarrollen actividades los trabajadores que, por negligencia o imprudencia, no observen las medidas de seguridad adecuadas a la actividad. $\mathrm{N}$ o debiera descartarse en tales casos la imposición de sanciones disciplinarias toleradas por la ley y prefijadas por la relación contractual civil o comercial entre la empresa principal y la contratista o subcontratista, según sea el caso ${ }^{32}$.

H uelga decir que seguridad y salud son bienes jurídicos diferenciados, no obstante lo cual ambos participan de algo en común: el ámbito de indemnidad de los trabajadores.

\footnotetext{
28 Solo para tener una idea, el país tiene un PIB a 2010 de 221.600 millones de dólares, siendo el 4,8\% de esa cifra: 8.864 millones de dólares. Sobre esto, Arenas de Mesa (1999) (fecha de consulta en internet, 21 de julio de 2011) pp.1 y siguientes.

29 "La prevención, la seguridad y salud en los ambientes de trabajo, forma parte del concepto de trabajo decente de sarrollado por la OIT y de la responsabilidad social de la empresa". http://www.il o.org/public/spanish/standards/ relm/ilc/ilc87/rep-i.htm\#F ortal ecimiento. Sobre estos conceptos, Cifuentes (2011) pp. 24.

${ }^{30}$ Gamonal et al (2010) pp. 98 y siguientes.

31 Dictamen 2.468 de 09.07.07, D irección del trabajo. También en Moraga (2009) pp. 524.

32 Sobre la existencia de este acuerdo, Lizama et al. (2009) pp. 19.
} 
Sin perjuicio de tal distinción, la referencia legal a la seguridad debe ser entendida como seguridad física y material, que lleva implícita una obligación de previsibilidad del riesgo para la empresa principal y la contratista o subcontratista33. En otras palabras, el criterio de previsibilidad, interpretado de forma objetiva, se equipara al de probabilidad del resultado. Así, la causa de un accidente que se deba a una falla en medidas de seguridad de un trabajador, hace que la causa de tal falla sea imputable al empleador 0 a la empresa principal de manera directa.

\section{APLICACIÓN DE LA PREVISIBILIDAD DEL HECHO Y EL DAÑO AL ESQUEMA DESUBCONTRATACIÓN EN EL CÓDIGO DEL TRABAJO}

Conviene preguntarse sobre el criterio de la previsibilidad en materia contractual y si este razonamiento es posible en materia laboral. Ello porque en materia de seguridad y salud laborales, estos deberes no quedan fijados en el contrato entre las partes, surgen, las más de las veces, de factores que se plasman durante la ejecución del vínculo contractual.

Lo propio de un deber de seguridad e higiene es que su incumplimiento sea aquilatado a la luz de una norma estatal, como es el caso chileno, y que su aplicación surja de la ejecución del contrato. En otras palabras, considera tanto la previsibilidad al tiempo del contrato como factor o criterio para la valoración de los daños provocados y la complementa con la previsibilidad de prevención y tratamiento del daño producido durante la ejecución del contrato. Lo anterior, de acuerdo al deber, impuesto por el legislador en el artículo 184 del Código del Trabajo, libro II De la Protección a los Trabajadores, de "tomar todas las medidas necesarias para proteger eficazmente la vida y salud de los trabajadores, informando los posible riesgos y manteniendo las condiciones adecuadas de higiene y seguridad en las faenas, como también los implementos necesarios para prevenir acci dentes y enfermedades profesionales. D eberá asi mismo prestar o garantizar los elementos necesarios para que los trabajadores en caso de accidente 0 emergencia puedan acceder a una oportuna y adecuada atención médica, hospitalaria y farmacéutica".

A nuestro juicio, esto es lo que debe alumbrar el criterio de imputación objetiva del fin de protección de la norma en materia de higiene y seguridad en el ámbito de la subcontratación. Existe un traslado del juicio de previsibilidad de la consecución de un

33 El Comité M ixto de la OIT y de la O M S para la salud en el trabajo, formuló en la ciudad de Ginebra, en 1985, una definición de "salud en el trabajo". Entre las conclusiones a las que llegó este Comité se encuentra la relativa a que las acciones en materia de seguridad y salud en el trabajo debían dirigirse directamente a la progresiva promoción y fomento de la salud de los trabajadores en el trabajo, señalando además que la protección de la salud de los trabajadores en estos términos no resultará en ningún caso posible de alcanzar si no se tienen en cuenta y se incorporan a las regulaciones y actuaciones los caracteres propios de la organización del trabajo. En este sentido, la duodécima reunión del Comité Conjunto de la O IT-O M S, en 1995, se incidió especialmente en las dimensiones psíquica y social de la salud estableciendo que las actividades relacionadas con la misma en el ámbito laboral, abarcan tres objetivos diferentes: el mantenimiento y la promoción de la salud de los trabajadores y su capacidad de trabajo; el mejoramiento del medio ambiente de trabajo y del propio trabajo a fin de garantizar la seguridad y la salud en el mismo; y la elaboración de sistemas de organización del trabajo y de culturas laborales con miras a fomentar la seguridad y salud en el mismo y de promover así un clima social positivo e incrementar la productividad de las empresas. Para más detalles: MarTín (2006) pp. 77-78. 
resultado dañoso, desde el momento temporal y propio del acaecimiento del curso causal, al momento de la valoración normativa que subyace en cada disposición de seguridad y salud en el trabajo34.

D esde este punto de vista, no cabe duda que son los trabajadores los primeros llamados a reclamar por la precariedad o inexistencia del deber de seguridad del empleador en la faena. Estos son libres para ejercerlo y hacerlo valer, pero en el caso de que no lo hagan, no por ese simple hecho el empresario principal o contratista quedará eximido del cumplimiento de las obligaciones que le correspondan, ni tampoco de las responsabilidades emanadas de su incumplimiento, que en la ley tiene el carácter de directa35.

La seguridad del trabajador debe estar orientada a que estos sean conscientes de que, haciendo un uso adecuado de los medios de seguridad propios de sus trabajos, en condiciones normales y siguiendo las instrucciones relativas al mismo, minimizarán casos de riesgo para su salud o integridad física.

No queda la menor duda que en la práctica frente a esta obligación debe generarse colaboración entre trabajador y empleador. Ello equivale a que la seguridad tiene un fuerte componente preventivo que está íntimamente relacionado con la protección de la salud e integridad física de los trabajadores, pero con ayuda de los propios trabajadores también.

Resulta claro a estas alturas que el examen de previsibilidad del empresario principal en relación al hecho, tiene un juicio previo que consiste en la existencia u omisión de las medidas de seguridad, y especialmente de control, de las conductas de riesgo o hechos que pueden acarrear daños cuando las labores se realicen en la empresa principal36. La previsibilidad del daño, en cambio, se genera después, cuando el deber de conducta no se ha materializado en la prevención de las consecuencias del accidente y se causa un perjuicio a causa de un accidente. Esto debido a no arbitrar la empresa principal o contratista las medidas necesarias para que los trabajadores, en caso de accidente 0 emergencia, puedan acceder a una oportuna y adecuada atención médica, hospitalaria y farmacéutica.

Las consecuencias desde el punto de vista del juicio de responsabilidad son diferentes. Si no hay previsibilidad del hecho, se determinará la culpa como factor de atribución del responsable. Si no hay previsibilidad del daño, ello determinará la cuantía de la indemnización, la que siempre está en función de los perjuicios irrogados y no del grado de

\footnotetext{
34 Similar esquema al advertido en el derecho alemán, que como advertimos en la nota 21 de este trabajo, tiene obligaciones propias del deber de protección. Por todos, Deutsch (1966) pp. 558-559.

35 En algunas jurisdicciones se señala que este derecho a la seguridad sería un derecho "superprotegido", especialmente en el derecho italiano, así Natullo (1995) p. 21; SANTONi (1979), pp. 40-41.

36 En el Dictamen № 141/05 de 10.01.2007 de la D irección del Trabajo, se señala que: "En otros términos, estaremos en presencia de trabajo subcontratado, en tanto se trate de actividades perteneci entes a la organización de la empresa principal, aun cuando los trabajos, tareas o labores que implique la ejecución de la o las obras o servicios, se desarrollen en recintos o instalaciones ajenos a la empresa principal, dueña de la respectiva obra, empresa o faena. Atendido todo lo expuesto no cabe sino reiterar que para los efectos de determinar la existencia de trabajo en régimen de subcontratación, solo cabe atender, a si la empresa principal es dueña de la respectiva obra, empresa o faena, resultando irrelevante para estos efectos, el lugar o recinto donde deban desempeñarse los trabajadores del contratista. En relación con el mismo requisito, cabe señalar que la exigencia de que la empresa principal deba ser dueña de la obra o faena que debe realizar el personal subcontratado, significa que estas deben corresponder a actividades que pertenezcan a la organización de la empresa principal y que estén sometidas a su dirección, debiendo por lo tanto, excluirse de tal aplicación, a aquel las que no cumplan tal exigencia".
} 
culpa del agente causal del daño, culpa que solo en materia de responsabilidad civil debiera ser considerada como factor de atribución de la relación causal.

El propio fin de protección de la norma para estos casos no es más que aplicación de la buena fe con que debe ser cumplido un contrato, tanto por el empleador como por el trabajador, y a juzgar por nuestra jurisprudencia reciente, ello alcanza a las eventuales víctimas por rebote, si hay incumplimiento de la obligación de seguridad y no se sabe dónde se produjo la falla en la prevención: "Es en este contexto que el fallo alude al artículo 2329 del Código Civil, para señalar que también en sede extracontractual está prevista la presunción de culpa en el evento de incumplimiento y, en ese mismo sentido, alude también a la teoría del riesgo creado. Sin embargo, tales referencias no constituyen ni sustentan en forma exclusiva la decisión a que se arriba, por lo que no han tenido para la resolución del asunto la incidencia que supone la recurrente (... ) El desconocimiento de las circunstancias del fallecimiento no impide la aplicación del estatuto de responsabilidad extracontractual, ya que lo reprochado es la omisión en el deber de seguridad del empleador, quien frente a los actores responde tanto del hecho propio como del ajeno, siendo de su cargo la prueba destinada a eximirse de tal responsabilidad, de acuerdo a las reglas generales que el fallo ha respetado para la determinación de la imputabilidad" 37.

Lo que se espera es una racional ejecución de las acciones que puedan comprometer la vida, salud y seguridad de los trabajadores, porque si el daño llega a producirse, se mirará siempre el hecho que causa el daño como un riesgo previsible y evitable de mediar debida y elemental diligencia. Este será el hecho en que se fundará la presunción de incumplimiento del contrato de trabajo. Así, lo previsible y evitable, si hubiera concurrido cierta diligencia en este tipo de obligaciones, sería la evitación de un riesgo o lo que es lo mismo, si el daño se ha producido ha sido por el incumplimiento de la medida de protección adecuada.

D esde la óptica de la responsabilidad civil que subyace en esta obligación de seguridad es posible entender que la ley ha dejado en evidencia la importancia de un análisis de la previsibilidad del hecho a consecuencia de un accidente ocurrido en el régimen de subcontratación. Existe una obligación de la empresa principal en orden a prever las imprudencias no temerarias de los trabajadores subcontratados y coordina su seguridad a través de la relación con la empresa contratista.

D e todo lo señalado, nos parece que no debiera extrañar la tendencia en la jurisprudencia a entender que el descuido de los trabajadores no es causa de exoneración o moderación de la responsabilidad civil del contratista. Difícil de aceptar por los tribunales un punto como este, ya que el deber de tutelar eficazmente la salud de los trabajadores recae sobre el contratista, y debe abarcar las distracciones o imprudencias no temerarias en que pudieran incurrir los trabajadores, lo que alcanza de acuerdo a la ley a la empresa principal de forma "directa".

37 Fuentes con Codel co y Socamor (2011). 


\section{CONSECUENCIAS DE LA PREVISIBILIDAD EN LA OBLIGACIÓN DE SEGURIDAD: ARTÍCULO 66 BIS DE LA LEY 16.744}

El contenido y efectos de la obligación de seguridad se han determinado a través de un amplio conjunto de disposiciones de carácter normativo. Jurisprudencialmente la obligación de seguridad propia de la relación laboral de subcontratación se ha calificado como obligación de resultado -en el ámbito temporal de la duración del trabajo-, de manera tal que basta que el trabajador pruebe que ha sufrido un daño durante el trabajo o con ocasión de él para que la empresa principal y el contratista resulten obligados a su indemnización, salvo que este acredite que el daño procede de una causa no imputable a su falta de diligencia en el cumplimiento de su obligación de seguridad 38 .

El trabajador tiene derecho a que el contratista o subcontratista, y al mismo tiempo la empresa principal de manera directa, piensen cómo prevenir hechos que pudieren causarle daños durante el desempeño de jornada laboral ${ }^{39}$.

La obligación de seguridad del artículo 66 bis de la ley $\mathrm{N} 016.744$, que se relaciona con la previsibilidad del hecho que causa el daño, deja claro que el factor de imputación del vínculo causal para estas materias, se compone al menos de ciertas situaciones que no pueden faltar. Según la doctrina se han históricamente distinguido cinco principios de imputación subjetiva en materia de responsabilidad por seguridad y salud en el trabajo: el acto ilícito y culpable, el riesgo, los actos dañosos de los auxiliares, el principio de confianza y la indemnización a causa de un sacrificio especial. La responsabilidad del empresario en materia de seguridad y salud en el trabajo, ante la inexistencia de una ley que determine su naturaleza objetiva, se debate entre los dos primeros principios: el principio de responsabilidad por culpa y el principio de responsabilidad por riesgo; conformando ambos principios verdaderos criterios de imputación ${ }^{40}$.

En el caso chileno nos parece que los trabajos que desarrollen los contratistas y/o subcontratistas deben ser efectuados en el marco de actividades laborales propias de la empresa principal, la ley las Ilama "de su giro". N o solo ello aparece necesario de acuerdo

\footnotetext{
${ }^{38}$ Similar situación a la que se observa en las obligaciones de seguridad propias de las relaciones laborales en general. "La obligación de seguridad del empleador se considera en los hechos como una obligación de resultado, cuyo incumplimiento se presume s ha ocurrido algún accidente, a menos que se acredite fehacientemente que el accidente obedece a caso fortuito, una causa de exoneración en al gún caso admitida (... ) raramente los tribunales atribuyen el accidente a caso 0 a negl igencia de la víctima que se expuso imprudentemente al daño por no tomar las medidas de seguridad dispuestas por la empresa". Rodríguez (2011) pp. 83, 95 y siguientes, donde cita varios ejemplos.

${ }^{39}$ Ello se colige del artículo 183 y 184 del Código del Trabajo, además de la ley № 16.744 de accidentes del trabajo y enfermedades profesionales, artículo 66 bis, y el propio decreto supremo N N 76, de Previsión Social, de 2007. Sobre estos extremos: Melis et al. (2009) pp. 198 y 199.

${ }^{40}$ GutiérRez-Solar (2004) pp. 24-25, señala esta misma autora un punto de vista que en principio no compartimos cual es que: "La responsabilidad por riesgo solo puede ser responsabilidad extracontractual (... ) Se trata de una responsabilidad que se sitúa más allá de la órbita estricta del contenido del contrato, aunque su justificación encuentre su causa en el mismo" pp. 49-51. No compartimos esta afirmación, por cuanto nosotros consideramos que el propio contrato es una forma de asignación de los riesgos de una relación jurídica entre las partes. Son estas las que asignan y sancionan riesgos en las cláusulas de un contrato, sujetas al incentivo que plantea un incumplimiento y sus consecuencias indemnizatorias.
} 
a la ley o los reglamentos, sino que debe, además, efectuarse bajo la responsabilidad de la empresa principal, lo que supone el control de la actividad por parte de la empresa principal. No es importante para estos efectos que la actividad sea en un lugar edificado o en lugares de trabajo al aire libre, bastará más bien en tal sentido que los trabajos se hagan con personal que tenga una relación laboral establecida con la empresa contratista o subcontratista ${ }^{41}$.

D esde el punto de vista del tribunal Ilamado a resolver un problema de responsabilidad civil en estas materias, no debe perderse nunca de vista que se necesita una valoración de aquellas conductas que causan daño. Siempre la responsabilidad por riesgo presupone actuaciones voluntarias de quienes precisamente han creado el riesgo, por la misma razón, una responsabilidad por riesgo no es una responsabilidad objetiva. Si el empresario principal incide y crea el peligro en el trabajo por omisión de su deber de seguridad, ello es un acto voluntario, y como tal, si ocurre el hecho que causa el daño, será responsable el empresario de ello.

En estas materias de subcontratación, la culpa del agente causal del daño deriva del deber propio incumplido por el deudor en la disciplina del contrato. Así, la responsabilidad que se deriva de determinadas medidas de seguridad que habrían sido legalmente adecuadas y propias de un actuar diligente, podrían haber llegado a impedir un accidente laboral o en cualquier caso, contribuir a atenuar la gravedad de los daños y las cuantías de los resarcimientos. En consecuencia, el incumplimiento contractual debe estar relacionado con un hecho que se liga con lo acordado por las partes en el contrato y que se desencadena dentro de un desarrollo normal del contenido negocial.

El deber de seguridad emanado de esta particular relación contractual de subcontratación exige que las dependencias o instalaciones, instrumentos, herramientas de trabajo, estén en óptimo estado. Ello garantiza que la precaución propia del trabajador sea un factor importante, mas no determinante en los accidentes que pudieran producirse en una obra o faena en régimen de subcontratación.

Como hemos apuntado anteriormente, el sistema de seguridad está pensado para prevenir, pero también para mitigar el daño producto de un accidente. En este sentido han fallado nuestros tribunales: "El objetivo es proteger la vida y salud de los dependientes. El modo es holístico, como quiera que alcanza a todo cuanto necesario para que lo anterior

\footnotetext{
${ }^{41}$ Es así como en el Boletín N ․ 2.493-13, de 16.05.06, que contiene el informe de la Comisión de Trabajo y Previsión Social de la H. Cámara de Diputados, en tercer trámite constitucional, se contó con la intervención del Sr. M inistro del Trabajo y Previsión Social O svaldo Andrade Lara, el que, en lo que nos interesa, señaló: "En efecto, no existe fundamento legal ni jurisprudencial para circunscribir la empresa o la faena a un ámbito espacial o físico determinado. Lo anterior resulta evidente de aplicar el concepto legal de empresa, ya sea aquel considerado en el artículo 3이 del Código del Trabajo o aquel incorporado, específicamente a propósito del trabajo en régimen de subcontratación, en el texto legal aprobado por la H onorable Cámara de Diputados. En aplicación de ambos con ceptos resulta plenamente posible que las labores desarrolladas por un trabajador en régimen de subcontratación se ejecuten en instalaciones ajenas al dueño de la obra o faena o empresa mandante, no obstante lo cual tales actividades laborativas deben ser consideradas como desarrolladas en régimen de subcontratación para este último, en tanto se trata de actividades que pertenecen a su organización y que se encuentran sometidas a su dirección". Párrafo reproducido en el O RD .: № 141/05 de 10.01.2007 de la Dirección del Trabajo. Sobre el particular, también se explaya MeLis et al. (2009) pp. 179 y siguientes.
} 
sea eficaz, esto es, con la aptitud o capacidad de alcanzar o lograr esa protección. D entro de la obligación que se comenta se comprende los resguardos en la faenas, los implementos para prevenir los accidentes; y los elementos que son menester para que en casos de accidente 0 emergencia los trabajadores puedan acceder a atención médica, hospi talaria y farmacéutica oportunas y adecuadas" 42 .

El sistema de seguridad en el régimen de subcontratación supone que la asunción del riesgo por el trabajador no sea relevante y la falla de tan solo uno de los elementos de seguridad propios de la actividad contratada, hace entender al sentenciador que debe acoger el principio de la responsabilidad por el riesgo creado.

Si el ordenamiento jurídico, como es el caso de la subcontratación laboral, optó por un régimen de culpa en estos casos, lo hizo como una opción de política jurídica en la que el factor de peligrosidad es uno de los elementos que se deben tener en cuenta en la realización de la actividad de los trabajos en el marco legal de la subcontratación y que depende de los estándares de seguridad y salud en el trabajo, comportamientos que en cierto modo, salvo normativa particular, están creados, dirigidos y coordinados en la libre determinación del empleador en la organización del medio ambiente de trabajo, una potestad que le es propia ${ }^{43}$. En este marco de seguridad es evidente que deberán tomarse en cuenta factores tales como los riesgos incurridos por la propia víctima, el cumplimiento de las directrices de seguridad, las medidas de protección adoptadas, los posibles daños, entre otros ${ }^{44}$.

La nueva obligación de seguridad que dejó establecida la ley 20.123 en nuestro país, que modificó el artículo 183 del Código del Trabajo, además del decreto supremo № 76, de Previsión Social de 2007, nos transmiten una idea clara, definitiva, la empresa principal que contrata o subcontrata obras, faenas o servicios propios de su giro, y que en ellas trabajan en su conjunto 50 o más trabajadores, está obligada a vigilar el cumplimiento por parte de dichos contratistas o subcontratistas de la normativa relativa a higiene y seguridad. N os parece que este es el centro de la idea legislativa de la subcontratación y que define ampliamente el porqué aparece tan difícil a un empresario principal en la práctica liberarse de responsabilidad frente a un accidente del trabajo en tribunales.

\section{INCENTIVOS DEL SISTEMA DE SUBCONTRATACIÓN CREADO POR EL ARTÍCULO 183 Y SIGUIENTES DEL CÓDIGO DEL TRABAJO}

El contratista, la empresa principal o subcontratista, según el caso, deberá cumplir con todas las indicaciones legales y reglamentarias que hemos expuesto y expondremos, pero si sostiene que sus directrices eran suficientes, conocidas, entregadas y enseñadas a sus trabajadores mediante sendas capacitaciones sobre seguridad y riesgos, no bastará para

\footnotetext{
42 O rellana Pavez, Cristián M. con Confortaire Ingeniería y Servicios Ltda. 2010. En este caso las demandadas Confortaire Ingeniería y Servicios Ltda. y SC L Terminal Aéreo Santiago S.A. Sociedad Concesionaria debieron pagar, solidariamente, a Cristián M auricio O rellana Pavez la suma de tres millones de pesos (\$3.000.00) por concepto de indemnización del daño moral causado directa e inmediatamente por el accidente del trabajo.

${ }^{43}$ Deutsch (1966) pp. 61 y 65. Gamonal et al. (2010) pp. 88 y siguientes.

${ }^{44}$ Huber (1973) pp. 309-310.
} 
exculparle en caso de que un daño se produzca durante la ejecución de la faena laboral45. $\mathrm{H}$ ay claramente en la nueva reglamentación un incentivo en este sentido.

No podrá ampararse la empresa principal en la falta de pericia o cuidado de sus trabajadores dependientes o los de la empresa contratista o subcontratista, porque no cesa su responsabilidad con cumplir con todas estas obligaciones de empresa, sino que, además, debe vigilar que tales medidas se cumplan.

La empresa principal deberá demostrar, sin ninguna duda para el sentenciador, que dio cabal cumplimiento a la prevención del hecho que causa el daño, que manejó y administró el daño una vez que este se produjo y que supervisó, como empresa principal, lo que la empresa contratista o subcontratista hacía ${ }^{46}$.

Si uno pudiera leer entre líneas estas normas, nos parece que el mensaje es meridianamente claro, casi diáfano: si la empresa principal no va a hacer dependientes a los trabajadores subcontratados, si no va a hacerse cargo directamente de sus obligaciones laborales y previsionales, en cuanto a sus obligaciones de seguridad, deberá vigilar que se cumplan estas obligaciones. Sin duda, estamos frente a otro incentivo planteado en la ley.

Los trabajadores subcontratados tienen derecho a una protección eficaz, esto legítima y empodera a los propios trabajadores a exigir directamente a las empresas principales y contratistas o subcontratistas el cumplimiento de esta obligación ${ }^{47}$. Lo dicho no obsta a

${ }^{45}$ En este sentido una sentencia reciente señala: "En la especie, la empresa principal no ha dado cumplimiento a la obligación que le impone la ley, ya que solo se limitó a la entrega de un reglamento especial y plan de trabajo de prevención de riesgos y a la designación de un encargado de implementar y mantener el funcionamiento del sistema de gestión de la seguridad y salud en el trabajo, pero nada dijo sobre la vigilancia que exige la ley. Por ello, la demandada es directamente responsable en el accidente del actor. Germán Silva Valencia con S Y R Tecnología y Servicios Integrales (2010).

${ }^{46}$ Como aclara un fallo ya citado:"70) Q ue, por consiguiente, la demandada VTR Banda Ancha, como empresa principal, no ha dado cumplimiento a la obligación que le impone la ley, ya que de los antecedentes aparece que se limitó a la entrega de un reglamento especial y plan de trabajo de prevención de riesgos, cuyo contenido no se conoce en autos y a la designación de un encargado de implementar y mantener el funcionamiento del sistema de gestión de la seguridad y salud en el trabajo (fojas 147, 148 y 149), pero nada habla de la vigilancia que exige el artículo 66 bis de la Ley N 016.744 y que hace aplicable el artículo 183 E del Código del Trabajo. No se trata ya de una vigilancia en situ, en la casa en que debía hacerse la conexión de cable sino de una política de fiscalización, de verificación, a que largamente nos extendimos en estos dos últimos considerandos. Nada indica acerca de la puesta en práctica de acciones de coordinación. Sobre entrega de implementos en condiciones de ser usadas, tampoco. D e ahí, queVTR Banda Ancha S.A., demandada en estos autos, sea directamente responsable en el accidente del trabajo sufrido por el actor". Germán Silva Valencia con S Y R Tecnología y Servicios Integrales (2010).

${ }^{47}$ Así queda de manifiesto en una sentencia que expresa "que la empresa individual tenga una responsabilidad directa, no significa otra cosa, en este contexto, que se la pueda demandar independientemente del contratista por su propia responsabilidad, pero no elimina la solidaridad pasiva que la ley etableció respecto de las obligaciones laborales y previsionales que esta adquiere. Por tal razón no es una obligación simplemente conjunta". Ramos con Asegim. (2010). En el mismo sentido, en otro fallo: "Establecida la responsabilidad de la empresa contratista, responde de manera solidaria quien encargó la ejecución de la obra, sin que a su respecto sea necesario establecer elementos subje tivos de imputabilidad, como son el dolo o la culpa, sea en el accidente como en la resolución del respectivo contrato". González con M arineer (2010). Sin embargo, en esto hay al guna sentencia en sentido diverso: "La demanda de indemnización solidaria por accidente laboral no puede prosperar, toda vez que la empresa principal no responde solidariamente de las obligaciones del contratista, sno en forma directa, según se ha ido uniformando en la doctrina y jurisprudencia, responsabilidad que fluye de los artículos del Código del Trabajo $183 \mathrm{E}$; 66 Bis de la Ley 16.744 y artículos $3^{\circ}$ del Decreto Supremo 594 de 1999, en cuanto radica también en la empresa principal la obligación de seguridad de los trabajadores, además de la del contratista en igual sentido". N avarro con Sociedad. (2009). 
que exista o concurra también un interés general comprometido, y que con ello se cumpla con un anhelo del cuerpo social cual es disfrutar de un ambiente de trabajo seguro y condiciones aptas de trabajo. Tal y como expresa un autor: "Las normas sobre subcontratación incorporadas por la L ey $\mathrm{N} 020.123$, persiguen dos ti pos de objetivos bien precisos y delineados de forma clara: el establecimiento de un sistema de incentivos, lograr un efectivo cumplimiento de las obligaciones laborales y previsionales que afectan a las empresas contratistas y subcontratistas respecto a sus trabajadores; y el fortal eci miento de las normas sobre protección de la seguridad y salud de los trabajadores en régimen de subcontratación. El di seño descrito configura la subcontratación como un mecanismo protector de los derechos de los trabajadores subcontratados. Es esta la filosofía detrás de la nueva configuración legal de la subcontratación" 48.

En la consecución de estos objetivos, los órganos administrativos también deberán concentrar su acción, sobre todo preventiva, de accidentes del trabajo $0^{49}$. Este nuevo marco legal: "... discurre sobre la base de que es la empresa principal la que etá en condiciones de diseñar un sistema de gestión de la seguridad en la faena, que establezca condiciones seguras para todos los trabajadores que en ella laboran, sean propios o externos, dado que los riesgos no se diferencian entre unos u otros" 50 .

No es de extrañar entonces que el Artículo 9 del reglamento 76 sobre el artículo 66 bis de ley 16.744, imponga una obligación de seguridad que establece una política de seguridad y salud en el trabajo y que establecerá las directrices que orientarán todos los programas y las acciones en materias de seguridad y salud laboral en la obra, faena o servicios. Supone, además, una organización que deberá señalar la estructura organizativa de la prevención de riesgos en la obra, faena o servicios, indicando las funciones y responsabilidades en los diferentes niveles jerárquicos, en particular la correspondiente a la dirección de la o las empresas; el o los Comité(s) Paritario(s); el o los D epartamentos de Prevención de Riesgos y los trabajadores.

La planificación deberá basarse en un examen o diagnóstico inicial de la situación y revisarse cuando se produzcan cambios en la obra, faena o servicios. Este diagnóstico deberá incluir, entre otros, la identificación de los riesgos laborales, su evaluación y análisis, para establecer las medidas para la eliminación de los peligros y riesgos laborales o su reducción al mínimo, con miras a prevenir las lesiones, enfermedades y muertes ocasionadas por el trabajo.

La identificación de las actividades peligrosas resulta fundamental y para ello la propia normativa que regula este tipo de actividades, es un elemento sine qua non de análisis del riesgo $0^{51}$.

\footnotetext{
${ }^{48}$ Lizama et al. (2009) p. 191.

49 Son dictámenes de la Dirección del Trabajo relativos a este tema: 0 rd. № 141/05 de 10.01.07; 0 rd. № 2.468/053 de 09.07.2007; 0 rd. № 4.881/103, de 28.11.07. Por todos, comentan estos dictámenes Melis et al. (2009) pp. 178 y siguientes; también en Moraga (2009) pp. 523 y siguientes. D e no ser así, sería realmente una carga para el contratista, sobre ello, Моnтuschi (1989) pp. 64-65.

50 O rden de Servicio N ㅇ 8. de 05.04.2007, Dirección del Trabajo.

51 Por ejemplo, los trabajos que suponen largas jornadas al sol o con exposición a radicaciones ionizantes en zonas controladas, actividades con exposición a agentes tóxicos, como ocurre en la minería, por la manipulación de maquinaria pesada o materiales voluminosos o explosivos, por citar algunos. Así, ley 20.001 que regula el peso máximo de carga humana; Reglamento sanitario sobre manejo de residuos peligrosos $N^{\circ} 148$ de
} 
El sistema fue diseñado para ser evaluado periódicamente lo que constituye un incentivo en la prevención, nos referimos al sistema de gestión, evaluación que corresponde hacerla en los distintos niveles de la organización. La periodicidad de la evaluación la establecerá, y es su deber, la empresa principal para cada obra, faena o servicios en régimen de subcontratación. El avance de los conocimientos científicos y técnicos debiera estar considerado en tal evaluación periódica de las medidas de seguridad. Es, desde este punto de vista, un deber u obligación de medios y no de resultados, así como una obligación permanente y de adaptación variable en el tiempo.

En este sentido, la acción en busca de las mejoras debe partir de mecanismos para la adopción de medidas preventivas y correctivas en función de los resultados obtenidos en la evaluación definida previamente, de manera de introducir los perfeccionamientos que requiera el sistema de gestión.

A estas alturas queda claro que no se trata de un simple sistema de protección que involucra una obligación de seguridad, como tampoco de una responsabilidad subsidiaria de la empresa principal, hoy derogada, sino de una obligación de seguridad activa, directa como señala la ley, que se adapta y evoluciona de acuerdo con las necesidades propias de la obra o faena contratada por la empresa principal 52.

Es más bien esta nueva obligación de seguridad, una auténtica actividad de precaución, la aspiración de una actividad de salvaguarda contractual de la integridad de la persona del trabajador. La propia Dirección del Trabajo precisa que se "(... ) establece una responsabilidad directa sobre la materia para la empresa principal, quien debe asumir tales obligaciones respecto de todos los trabajadores que laboren en su obra, empresa o faena, cualquiera que sea la dependencia de estos, ya sea, en virtud de lo dispuesto en el artículo 66 bis de la Ley $N \cong 16.744$, sobre acci dentes del trabajo y enfermedades profesionales 0 de acuerdo al artículo 3ำ del D ecreto Supremo N 0 594, de 1999, del M inisterio de Salud" 53.

Este verdadero plan de protección, implícito en el sistema de seguridad, tiene como objetivo la programación de la política preventiva en la empresa, en relación a la faena, obra o servicio que realiza, si miramos esto desde el punto de vista de la empresa principal o la contratista54. Sin embargo, no se subentiende que de su incumplimiento se haya producido un perjuicio, sin daño no hay responsabilidad.

12 de junio de 2003, del M inisterio de Salud; D ecreto $N^{\circ}$ 133, Reglamento sobre autorizaciones para instalaciones radiactivas o equipos generadores de radiaciones ionizantes, personal que se desempeñe en ellas, u opere tales equipos y otras actividades afines, de 22 de mayo de 1984, ley número 20.096 de 23 de marzo de 2006, que estableció y reguló los mecanismos de control aplicables a las sustancias agotadoras de la capa de ozono estratosférico y a los productos cuyo funcionamiento requiera del uso de dichas sustancias, las medidas destinadas a la prevención, protección y evaluación de los efectos producidos por el deterioro de la capa de ozono, debidos a la exposición a la radiación ultravioleta, y las sanciones aplicables a quienes infrinjan dichas normas, entre otros cuerpos legales.

52 Sobre el tema en perspectiva histórica: Gumucio et al (2011) pp. 84 y siguientes. Lizama et al. (2009), pp. 50. 53 Dictamen N 141/05 de 2007 sobre Trabajo en Régimen de Subcontratación. Para un análisis lúcido en la materia, MeLis et al. (2009) pp. 179 y siguientes.

${ }^{54}$ En un fallo reciente se especifica el alcance de estas obligaciones en el caso de empresas que trabajan con pesticidas: "Corresponde rechazar el recurso de apelación interpuesto por la reclamante, puesto que contrario a lo alegado por ella, ti ene responsabilidad en las conductas de la empresa que aplica pesticidas, toda vez que de acuerdo al artículo 183 E del Código del Trabajo y otras normas regl amentarias, debe proteger la salud e integridad física de 
Como puede apreciarse, son obligaciones de la empresa principal explicar las características esenciales de la actividad de riesgo por medio de instrucciones, advertencias, consejos o recomendaciones, sobre instalación, uso y mantenimiento, manejo, manipulación, peligrosidad o condiciones de seguridad, en el caso de que dicha información sea necesaria para el cumplimiento de la obligación de seguridad en las faenas ${ }^{55}$. Se han de arbitrar, en tal caso, las medidas oportunas en orden a evitar los riesgos que para la salud de los trabajadores pudiese representar el uso inadecuado de los instrumentos de trabajo ${ }^{56}$. Se entiende que solo hay responsabilidad por una omisión imprudente cuando el que adopta ese comportamiento omisivo se encuentra en un previo contexto de garante, el que puede provenir de una norma o un contrato.

Esta verdadera profesionalización de la obligación de seguridad supone que se señalen, incluso, los controles necesarios para verificar el estricto cumplimiento de las condiciones de seguridad exigidas legalmente, todo ello orientado a garantizar un desempeño que minimice el riesgo en la actividad laboral.

Ante situaciones de riesgo potencial, se impone a los empresarios adoptar todas las precauciones, arbitrar medios y evitar que situaciones de trabajo se conviertan de peligro potencial en daño efectivo, lo que se traduce en la obligación de adoptar medidas de se-

sus trabajadores e incluso de aquellos sometidos a régimen de subcontratación. En efecto, el actual D ecreto Supremo $N^{\circ}$ 594, artículo $3^{\circ}$, cuya infracción entre otras dio origen a la multa, establece en sus disposiciones generales que la empresa está obligada a mantener en los lugares de trabajo las condiciones sanitarias y ambiental es necesarias para proteger la vida y la salud de los trabajadores que en ellos se desempeñan, sean estos dependientes directos suyos o lo sean de terceros contratistas que realizan actividades para ella. Refuerza la responsabilidad de la empresa reclamante lo prevenido en el artículo 183 E del Código del Trabajo, que prescribe que la empresa principal deberá adoptar las medi das necesarias para proteger eficazmente la vida y la salud de todos los trabajadores que laboren en su obra, empresa o faena, cualquiera que sea su dependencia en conformidad a lo dispuesto en el artículo 66 bis de la Ley 16.744 y el artículo $3^{\circ}$ del decreto supremo N ${ }^{\circ} 594$, de 1999 , del M inisterio de Salud. Esta norma se complementa con la del artículo 184 del Código Laboral". Puerto de Lirquén S.A. con Fisco de C hile (2010).

55 En el mismo sentido, Asúa González, para el mismo tipo de conductas omisivas y la responsabilidad que de ellas deriva, señala que: " (sic) En estas se dice que el tema es exclusivamente de imputación objetiva del daño y, por tanto, de determinación y aplicación de criterios de cara a decidir cuándo el que ha omitido una conducta debe ser responsable de un resultado que materialmente no ha causado. Amén de que a tal efecto puedan barajarse y aplicarse diversos criterios". Señala además, que " (sic) no cabe duda de que la responsabilidad sí debe establecerse en los casos en los que existe un deber jurídico de evitar un resultado lesivo y la acción debida y omitida tenga capacidad para evitarlo". Asúa (2010) p. 236. En nuestro país la evidencia pareciera abrumadora, ya que "(sic) D e concluirse que estos deberes son de resultado - que por lo demás no parece una conclusión tan extraña a la luz de la jurisprudencia de nuestros tribunales- la presencia del accidente del trabajo, más que la presunción iuris tantum, de incumplimiento contractual, sería en sí mismo el hecho que prueba objetivamente la infracción del contrato". BARAONA (2011) p. 157.

56 En el derecho comparado es posible llegar a establecer el criterio de imputación objetiva de la responsabilidad en el ámbito de las conductas omisivas. Así, R eglero señala que en al gunos ámbitos de la actividad económica o social generadora de riesgos, los problemas causales provienen de conductas omisivas, particularmente cuando sobre el responsable recae un deber de actuar o de información. D e no arbitrarse tales medidas, no habría seguridad o custodia. Concluye el mismo autor que un empresario que no cumple con los deberes de información, seguridad y vigilancia, incurre en una conducta antijurídica, que en un juicio de responsabilidad civil se traduce en imputación del vínculo causal en el caso de que se produzca un daño. Estas son obligaciones que al fin y al cabo ha impuesto la ley 20.123 en nuestro país, que modificó el artículo 183 del Código del Trabajo. En cualquier caso, en España hacen clara mención a estos deberes Reglero et al. ( 2002) pp. 61; 97 y 98 y Ramos (2007) pp. 11 a 38. 
guridad y control en la instalación en la que se realiza la obra o faena. Para D íez-Picazo esto es desconcertante, ya que "(sic) Curiosamente, el mismo sistema industrial y técnico, al multiplicar los daños, multiplica también las posibilidades de previsibilidad de estos daños y conlleva los elementos y las condiciones de seguridad y evitabilidad. Lo cual permite encontrar culpas donde antes no se hubieran jamás soñado. Y, si a ello se añade que el elemento de species facti no es solo el hecho del hombre, sino también sus omisiones (lo que se pudo hacer, lo que se debió hacer y no hizo) resulta muy claro que el panorama se complica extraordinariamente" 57 .

Sin lugar a dudas, la empresa principal responde de los actos de sus dependientes en quienes se deposite la responsabilidad de comunicar y vigilar el cumplimiento de tal obligación. Cada cual responde en este sentido por los trabajadores de cada empresa, la principal por los suyos, la contratista por sus dependientes. Sin embargo, frente al trabajador, cualquiera sea su dependencia, la responsabilidad es directa siempre de la empresa principal. Así lo deja claro el propio Decreto Supremo ${ }^{\circ} 594$, artículo $3^{\circ}$, que establece que la empresa está obligada a mantener en los lugares de trabajo las condiciones sanitarias y ambientales necesarias para proteger la vida y la salud de los trabajadores que en ellos se desempeñan, sean estos dependientes directos suyos o lo sean de terceros contratistas que realizan actividades para ella.

D e esta manera, la responsabilidad del contratista frente al trabajador será siempre contractual, pues el dependiente realiza una función que corresponde al empresario (contratista o subcontratista), y que deriva del contrato de trabajo. Es por ello también que el perjudicado deberá dirigirse directamente contra ellos para solicitar la reparación de los daños que se le hayan causado. Es esta precisamente la razón por la que la reclamación se fundamentará en las reglas de la responsabilidad extracontractual si el trabajador subcontratado demanda solo a la empresa principal, ya que no existe vínculo alguno entre el trabajador subcontratado y el empresario principal. La misma solución debiera darse si el que reclama es un tercero ajeno a la empresas8.

Señalábamos que esta obligación de seguridad es activa por cuanto, de acuerdo al reglamento y el Artículo 66 bis, son obligaciones primordiales de la empresa principal, entre otras, mantener en la faena, obra o servicios y por el tiempo que esta se extienda, un registro actualizado de antecedentes de las empresas contratistas, subcontratistas y de servicios transitorios, confeccionar un "Reglamento Especial para empresas contratistas y subcontratistas", el que será obligatorio para tales empresas. H ay que aclarar que este reglamento nada tiene que ver con el reglamento de higiene y seguridad de la empresa principal59. Este es uno específico para trabajadores subcontratados o de empresas de servicios transitorios. Se debe, además, velar por la constitución y funcionamiento de un Comité Paritario de Higiene y Seguridad de trabajadores subcontratados o de empresas de servicios transitorios, nuevamente distintos de aquel propio de la empresa principal. Y, por último, se debe vigilar por la constitución y funcionamiento de un D epartamento de Prevención de Riesgos para los referidos trabajos.

\footnotetext{
${ }^{57}$ Díez-Picazo (1980) pp. 732 y 733.

58 Sobre estos puntos, Prado (2009) pp. 66 y siguientes.

${ }^{59}$ Gamonal et al. (2010) pp. 101 y siguientes.
} 
Q ueda en evidencia que la obligación contractual de seguridad en el régimen de subcontratación beneficia, no solamente al acreedor, sino igualmente a los terceros que pudieran verse afectados por accidentes del trabajo60. Si se produce el daño, no es extraño entonces que se aplique el principio res ipsa loquitur, la falta se infiere del daño.

¿Q ué significa este conjunto de normas? ¿C uál es su incentivo? Q ue estamos frente a una clara "positivización" de las diferentes obligaciones expuestas. Ellas son concretas, irrenunciables, forman parte del deber de seguridad, todo ello con vistas a proteger de modo eficaz a sus trabajadores, y a los trabajadores subcontratados, en materia de seguridad laboral en el régimen de subcontratación. Esta obligación alcanza a los riesgos propios de la actividad laboral y no otros que pudieran darse y que no tuvieran relación con la actividad propiamente laboral.

Todo lo anterior no hace más que afirmar que el criterio para construir la imputación objetiva de las omisiones del empleador frente al deber de seguridad, pasa por la finalidad protectora de la norma ${ }^{61}$. Es claro que hay un deber contractual de seguridad que representa una garantía de cara al trabajador. Establece la existencia del nexo causal entre la omisión del contratista por la no adopción de medidas de seguridad y el daño causado, que arrastra en su incumplimiento e indemnización a la empresa principal. En este mismo sentido, el grado de exigibilidad es proporcional al riesgo relativo a la conducta o actividad de que se trata, esto porque en conductas omisivas, como esta, la doctrina está conteste en que el eventual responsable no cumple precisamente con aquella conducta que estaba llamado a cumplir, que no es otra cosa que un deber propio como el de información o seguridad62.

$60 \mathrm{El}$ registro de contratistas y subcontratistas se desprende del artículo $5^{\circ}$ del reglamento 76 sobre artículo 66 bis de ley 16744: "La empresa principal, para efectos de planificar y dar cumplimiento a sus obligaciones en materia de seguridad y salud en el trabajo deberá mantener en la faena, obra o servicios y por el tiempo que esta se extienda, un registro actualizado de antecedentes, en papel y/o soporte digital, el que deberá contener a lo menos:

a) Cronograma de las actividades o trabajos a ejecutar, indicando el nombre o razón social de la(s) empresa(s) que participar (n) en su ejecución;

b) Copia de los contratos que mantiene con las empresas contratistas y de estas con las subcontratistas, así como los que mantenga con empresas de servicios transitorios;

c) D e las empresas contratistas, subcontratistas y de servicios transitorios:

c.1) R.U.T y N ombre o Razón Social de la empresa; O rganismo Administrador de la Ley N ${ }^{\circ}$ 16.744; nombre del encargado de los trabajos o tareas, cuando corresponda; número de trabajadores, y fecha estimada de inicio y de término de cada uno de los trabajos o tareas específicas que ejecutará la empresa;

c.2) H istorial de los accidentes del trabajo y enfermedades profesionales de la faena. La empresa principal podrá solicitar información de la siniestralidad laboral a las empresas contratistas o subcontratistas;

d) Informe de las evaluaciones de los riesgos que podrían afectar a los trabajadores en la obra, faena o servicios;

e) Visitas y medidas prescritas por los organismos administradores de la Ley $\mathrm{N}^{\circ} 16.744$; y

f) Inspecciones de entidades fiscalizadoras, copias de informes 0 actas, cuando se hayan elaborado. Este registro deberá estar disponible, en la obra, faena o servicios, cuando sea requerido por las entidades fiscalizadoras. Existe, como expresamos antes, un Reglamento Especial para empresas contratistas y subcontratistas, propios del Artículo 11; 12; 13 del mismo reglamento 76 sobre artículo 66 bis de ley 16744. Un Comité Paritario de Faena que se encuentra regulado en los artículos 14 a 25 del mismo cuerpo legal y un Departamento de Prevención de Riesgos, reglamentado en el artículo 26 a 32 del reglamento 76 que nos ocupa.

${ }^{61}$ Carrancho (2010), p. 258.

62 Sobre el tema, Reglero et al. (2008) pp. 759 y 760. 


\section{LOS DEBERES CONTRACTUALES DE LOSTRABAJADORES SUBCONTRATADOS}

La obligación de responder del incumplimiento de las medidas de seguridad en el trabajo corresponde no solo a los empleadores, sino también a los trabajadores ${ }^{63}$.

Como puede apreciarse, la presencia de los trabajadores pertenecientes al contratista o subcontratista en el centro de trabajo de la empresa principal vincula a ambos empleadores al cumplimiento de las normas de seguridad e higiene sobre sus trabajadores subordinados, haciéndose más evidente el deber de seguridad en el caso de la empresa principal, por las razones legales en estudio en este trabajo.

Resulta claro que estas obligaciones deben custodiarse en su cumplimiento desde la perspectiva de la organización del lugar de trabajo, tarea propia de la empresa principal, como desde el punto de vista de la dirección de la actividad de los trabajadores, que corresponde al contratista o subcontratista.

Claro aparece entonces el punto de vista según el cual, la responsabilidad de la empresa principal tiene su fundamento en la culpa subyacente en el incumplimiento de su obligación de seguridad, la que no se presume o no debiera presumirse por el mero hecho de la subcontratación. Todo lo anterior corroborado por el hecho de que es esta una obligación directa, de acuerdo con nuestra actual legislación.

La relación de causalidad para casos de omisión de una conducta como los que exponemos, queda establecida por el hecho de que de haber sido observada la obligación de seguridad o información, se hubiera evitado, con alta certeza o con juicio de probabilidad adecuado, el resultado dañoso propio de actividades de riesgo.

63 Interesante resulta este punto en la minería, la A sociación Chilena de Seguridad en un estudio realizado el año 1998 estableció que el 30\% de los varones y el 20\% de las mujeres que habían participado en accidentes dieron positivo en los exámenes por consumo de drogas legales como ilegales. Esta fue la razón por la que hay regulaciones específicas para los trabajos de minería (DS 72) y por algunos dictámenes de la Dirección del Trabajo y de la Superintendencia de Seguridad Social, que en definitiva concluyen que si en la faena minera es sorprendido un trabajador bajo la influencia de alcohol o drogas, puede ser derivado por el supervisor ante el personal competente a realizarse un examen para verificar consumo, bajo sanción de expulsión inmediata del recinto de trabajo, con auxilio de la fuerza pública si fuere necesario en caso de negativa. Adicionalmente, las empresas pueden considerar en sus Reglamentos Internos de H igiene y Seguridad la realización de exámenes preventivos aleatorios y despersonalizados y también pueden realizar exámenes a quienes han participado en un accidente del trabajo. En Chile, en general, el consumo en la población laboral ha sido dimensionado por la Asociación Chilena de Seguridad en tres sucesivos estudios de investigación realizados los años 2003, 2007 y 2008 que han puesto de manifiesto las cifras de consumo en los distintos sectores de actividad económica estudiados (Servicios, Agrícola /Forestal, Comercio /Transporte, Industria y M inería). Los resultados generales, comparativos entre los años 2003, 2007 y 2008 muestran un aumento del porcentaje de bebedores problema de $26.3 \%$ a $34.0 \%$ y del consumo de drogas ilícitas de $2.7 \%$ a $6.0 \%$ y una disminución del consumo de me dicamentos psicotrópicos de $12.7 \%$ a $10.0 \%$ y de tabaco de $65.3 \%$ a $48.2 \%$. Sobre el tema, se explaya VArgas (2011), pp. 66 y siguientes. Para análisis en dictámenes sobre el particular Melis et al. (2009) pp. 178 y siguientes. También se puede encontrar información relevante en Asociación Chilena de SEguRidad (2008) "Reportes" pp. 54. Disponible en http://ww3.achs.cl/ws/wps/wcm/connect/ece6a3804fbe8c95af1bef080f4d3a2b/ BIRE_RS06.pdf?M O D =AJPERES\& CACH EID =ece6a3804fbe8c95af1bef080f4d3a2b (fecha de consulta 18 de octubre de 2011). 
La omisión de medidas de seguridad exige la existencia de nexo causal adecuado entre el siniestro del que se deriva la pérdida de la vida o la integridad física de los trabajadores y la conducta pasiva del empleador. La omisión, para decirlo en términos más claros, es el comportamiento pasivo ante el riesgo que amenaza un determinado bien 0 interés cuando existe la exigencia jurídica de actuar para eliminarlo 0 , al menos, reducirlo. Como señala un autor: "Contrae responsabilidad quien no actúa para evitar el daño cuando el hombre medio actuaría; cuando la gente considera obli gado el socorro, y el no presentarlo representa una infracción al deber de solidaridad y buena fe" 64 .

Los criterios que hemos señalado hasta hora tienen su centro, a no dudarlo, en la culpa subjetiva, la que se tamiza o forma a través de parámetros normativos propios de la reglamentación de la obligación de seguridad en la ley, haciéndola más exigente en su previsibilidad. Ello debe adherirse 0 analizarse junto a la buena fe propia del contrato de trabajo, la que alcanza a los trabajadores subcontratados también.

En el marco legal actual es posible establecer la existencia de un elemento anterior al contrato de trabajo, el deber de protección. Los deberes de protección son inherentes a toda relación negocial y suponen un comportamiento ceñido a un esquema ético-jurídico. Es cierto que en el derecho comparado laboral de nuestros días se ha ido pretiriendo tal dimensión y acrecentando la perspectiva de la buena fe objetiva. Sin embargo, es imposible no tomar en cuenta su perspectiva pues en la noción actual de estos deberes está, genéticamente, la moral o la ética propia de las relaciones humanas.

Recordemos que por influencia del derecho canónico en el D erecho civil o común, quien incumple el contrato comete una falta, es culpable. Todo ello atado y vinculado a la buena fe objetiva, regla de integración donde las haya, criterio de conducta leal que se desarrolla en función de la normativa instrumental propia del contrato, lo que nos hace arribar a la necesaria consecuencia de que los contratos de trabajo requieren, como cualquier otro, lealtad en las prestaciones debidas por las partes.

Es propia de cualquier contrato la injerencia en la esfera jurídica y personal de la contraparte, y que en el caso de la subcontratación supone el cruce con una amplia gama de deberes accesorios al marco de la relación principal. Es precisamente por lo anterior, que el legislador ofrece un sistema estructurado de prevención de riesgo bajo el concepto de lo previsible.

Los deberes que forman parte de esta relación contractual son los de aviso o comunicación, los de custodia, conservación o seguridad, y rescate. Todos ellos debieran integrarse a partir del propio artículo 1546 y 1558 del Código Civil, si de incumplimientos contractuales se trata. No cabe la menor duda que la deuda o crédito del empleador, frente a su trabajador-acreedor de la obligación de seguridad, supone que este conoce las circunstancias específicas del riesgo de la actividad que se desarrolla como trabajo65.

Vista así la culpa del trabajador subcontratado, perjudicado por un accidente laboral, principal defensa de las empresas principales o contratistas en juicio, se relaciona con

\footnotetext{
64 GonzÁlez (1996) p. 460. En este mismo sentido antes, Yzquierdo (1993) pp. 130-131.

${ }^{65}$ Así en Alvarez de la Rosa (1997) p. 58.
} 
un correcto uso de los instrumentos de seguridad66. De ahí que a la hora de medir el defecto de seguridad por parte del trabajador subcontratado, se deba tener en cuenta el uso que razonablemente pudiera esperarse de los medios para alcanzar el deber de seguridad exigido por ley (guantes, zapatos, cremas protectoras o vestimentas especiales, entre otros, aunque se manifiesta especialmente en los trabajos en instalaciones eléctricas o en las proximidades de líneas de alta tensión, esto gracias al peligro especialísimo envuelto en la realización de tales actividades).

Actúa culposamente un trabajador si no realiza un uso correcto, utiliza el medio de seguridad para fines inesperados e impropios del bien o les da un destino inadecuado 0 simplemente no los utiliza.

El trabajador debe comportarse de buena fe en el cumplimiento de las medidas de seguridad impuestas por el empleador. Cumple este punto un rol fundamental, a juzgar también por la jurisprudencia. Esto porque desde el punto de vista de la obligación emanada de un contrato de trabajo, representa la buena fe un instrumento de interdicción de exigencias abusivas del acreedor (trabajador), de su deudor de seguridad (empleador).

La buena fe del trabajador incide en la obligación propia del contrato de trabajo, ya que limita o extiende el ámbito de relevancia de las conductas lesivas del deudor más allá del interés de prestación, esto sucede por la integración del contrato con deberes de seguridad o protección. En efecto, es la buena fe la que protege la esfera de la obligación de la empresa principal o contratista de injerencias dañosas del trabajador acreedor de seguridad.

Es deber del trabajador tener atención o diligencia, lo que significa que debe cumplir las medidas de seguridad. Para la valoración de esa conducta tiene especial importancia la información que el contratista proporcione a los trabajadores, por ejemplo, la presentación del producto o medida de seguridad. Esta, además, debe adecuarse a esos usos razonablemente previsibles ${ }^{67}$. Si se atenta contra estos deberes de seguridad por parte del empleador, se expandirá la responsabilidad contractual, en otras palabras, aumentará la indemnización del daño irrogado al trabajador68. El hecho de que la empresa haya informado e instruido convenientemente al trabajador sobre las condiciones de seguridad de las instalaciones y artefactos, no la libera en caso de producirse un daño, debe además vigilar su cumplimiento, como ya hemos tenido oportunidad de analizar.

La relación laboral, que es en su núcleo es una relación de "intercambio", no puede transar la vida, la integridad psicofísica ni la salud del trabajador, sino tan solo su prestación de servicios.

\footnotetext{
66 En otros ordenamientos se considera que la relevancia de la culpa de la víctima ha de limitarse a aquellos supuestos en los que se haya probado que el trabajador ha asumido personal y de manera libre, consciente y notoria un riesgo, incumpliendo las órdenes concretas, precisas y claras del empresario o empleador; así como a los supuestos de autolesión del propio trabajador. Esto es, solo en el caso de que el empresario haya cumplido y haya exigido de manera clara y expresa al trabajador la utilización de determinados instrumentos de seguridad y una determinada forma de realizar la actividad, haciendo el trabajador caso omiso de estas exigencias, solo así puede fundarse la concurrencia de culpa de este. Luque (2003) pp. 63 y 64.

67 JORDANO (1987), p. 318.

68 Sobre estos puntos, Prado (2009) pp. 93 y siguientes.
} 
El trabajador no puede vender al contratista, y por su intermedio el empresario principal, no puede comprar o pretender comprar de algún modo la salud y bienestar de sus propios trabajadores subordinados o de aquellos que hayan sido subcontratados a partir de una relación propia de este tipo69.

El trabajador en materia de prevención de riesgos laborales debe someterse a la dirección, mando y potestad del empleador. No posee libertad en este punto. De la normativa estudiada, no puede el trabajador elegir si cumple o no con las medidas de seguridad dispuestas por el empleador. Es por ello que el incumplimiento de tales directrices, supone en el juicio de responsabilidad, incumplimiento de deberes de autoprotección y, por lo tanto, debiera limitar la responsabilidad del empleador, y por qué no, si fuera del caso, extinguirla.

No puede menos que concluirse, en fin, que la responsabilidad empresarial debiera excluirse cuando la producción del evento que acontece lo hace de manera fortuita, imprevista 0 imprevisible. Ello deja patente que ninguna responsabilidad cabe al empleador si ha cumplido con todas las normas de prevención, ya que en tales supuestos, el accidente se pudo haber producido entonces por imprudencia del propio trabajador accidentado.

El deber del empresario es la otra cara de la moneda de los derechos de los trabajadores. La responsabilidad de la empresa contratista y la principal frente al trabajador es contractual, habida cuenta de la obligación "directa" de carácter legal que impone la ley a este último, y tiene como fundamento una obligación de seguridad o garantía, que asumen las citadas empresas en la forma en que hemos venido describiendo junto a los propios trabajadores también. Esta obligación acompaña al contrato oneroso, y es de las Ilamadas de resultado o de fines, sin perjuicio que en su ejecución deben someterse al estado de la lex artis. Los contratistas se eximen de responder cuando prueban: 1) la culpa de la víctima (en el ámbito extracontractual exclusivamente); 2 ) el hecho de un tercero por quien ellos no deban responder (discutible en la responsabilidad contractual), y 3) el caso fortuito.

A. ¿Es CORRecto el uso de la terminología Culpa de la víctima en estos INCUMPLIMIENTOS CONTRACTUALES?

La culpa de víctima es una categoría propia de la responsabilidad extracontractual, y dentro de ella, una manera de disminuir la cuantía del resarcimiento de acuerdo al artículo 2330 del Código Civil70. Bajo este estatuto se infringe un deber general de comportamiento que supone que nadie debe causar daños a otros, partiendo por la propia víctima. Es cierto que ha de haber un concurso de causalidad71, pero más que ello,

\footnotetext{
${ }^{69}$ Martín (2006) p. 48. Recientemente en el mismo sentido, LaI (2010) pp. 47 y siguientes; y también MonTUSCHi (2006) pp. 1 y 3.

70 Sin perjuicio de lo cual alguna sentencia lo señala, así la C orte de A pelaciones de Antofagasta: "D ebe considerarse que el actor se expuso imprudentemente al daño al ejercer funciones para las que no estaba capacitado, situación que solo se tendrá presente para los efectos de regular la indemnización por daño moral de conformidad con lo dispuesto en el artículo 2330 del Código Civil, mas no, para eximir de responsabilidad a las empresas demandadas". González con M arineer (2010).

71 Domínguez (2011) p. 33
} 
deben concurrir multiplicidad de factores de atribución causal y de previsibilidad del hecho que causa el daño a nuestro entender.

Si de contratos se trata, no hay culpa de la víctima, hay derechamente incumplimiento contractual, específicamente de deberes contractuales del acreedor de tal relación laboral: el trabajador. Así lo ha afirmado ya la jurisprudencia: "En consecuencia, habiendo el trabajador incumplido con las obligaciones impuestas por el Reglamento de Seguridad, el M anual de Procedimiento de la empresa, y las reglas del M anual de Procedimiento sobre la forma en que los (sic) motosierrista deben ejecutar su labor, es dable afirmar que el accidente no se originó en infracción por parte del demandado principal, a la obligación de seguridad que sobre él pesaba, sino que más bien se produjo por violaciones contractuales y reglamentarias del propi o trabajador, en términos tales que eliminan la responsabilidad de la sociedad empleadora en el accidente sufrido. Lo que conlleva el rechazo de la demanda deducida en contra de las dos empresas demandadas" 72 .

En este punto hay que insistir, ninguna relación puede haber entre el incumplimiento de la obligación de seguridad del empleador y el incumplimiento de la obligación de seguridad del trabajador desde el punto de vista contractual, porque el contratista se libera de su deber de cuidado probando que cumplió con la prevención del hecho que causó el daño y las consecuencias de él. En tal escenario, no pueden imputársele los daños irrogados a la víctima.

El incumplimiento del deber de conducta propio del contrato por parte del trabajador en realidad es una forma de imputación objetiva del juicio de culpa frente a la observancia de su obligación contractual. Esta inobservancia, en caso alguno exime al empleador de su propio deber de seguridad.

N os parece fundamental separar vínculos causales en esta materia, el simple hecho de que sean un trabajador o un tercero los que hayan colaborado a que se produjera un daño dentro de una relación laboral, no obsta a que se determine en el juicio de responsabilidad si el empleador no ha respetado las leyes que ordenan deberes de seguridad. Esto, fundamentalmente, porque de haberse cumplido esta diligencia y la observancia del deber de seguridad por parte del empleador, este podría haber disminuido o eliminado la incidencia causal de la conducta negligente del trabajador o un tercero que causaron el daño.

0 tra diferencia capital en esta materia es que en la responsabilidad por el hecho ajeno, propia de la responsabilidad extracontractual, ideas como la falta de diligencia o cuidado, la previsibilidad o evitabilidad se refieren al empleador predominantemente. Esto es así porque es sobre el empleador el que pesaba vigilar a su trabajador durante la jornada y responderá por haberles el egido mal para realizar las tareas. Es una falta a consecuencia de su incompetencia en la elección.

72 D e esta forma expresamente en la sentencia N avarro con Soci edad (2009). 


\section{LA FISCALIZACIÓN DE LA OBLIGACIÓN DE SEGURIDAD EN EL RÉGIMEN DE SUBCONTRATACIÓN}

Esta obligación de seguridad que hemos caracterizado como dinámica debe ser fiscalizada, en principio, de acuerdo al artículo 34 de la ley 16.744: "La fiscalización de este reglamento corresponderá a la D irección del Trabajo, a las Secretarías Regionales M inisteriales de Salud, a la superintendencia de Seguridad Social (en adelante SU SE SO ) y a las demás entidades fiscalizadoras, de acuerdo a sus competencias" 73.

La SU SESO interpreta y fiscaliza el Seguro Social de Accidentes del Trabajo74; la autoridad sanitaria y fiscalizadora compete a los Servicios de Salud75; la D irección del Trabajo (en adelante DT ) que controla la constitución y funcionamiento de los Comités Paritarios de H igiene y Seguridad que deben funcionar en las empresas ${ }^{76}$; el Servicio N acional de Geología y M inería (en adelante SERN AGEO M IN ) que vela por el cumplimiento de los reglamentos de policía y seguridad minera y la aplicación de las sanciones respectivas a sus infractores; y propone la dictación de normas que tiendan a mejorar las condiciones de seguridad en las actividades mineras 77 ; el Instituto de Salud Pública (en adelante ISP) ${ }^{78}$; la Dirección General del Territorio M arítimo y de M arina M ercante (en adelante DIRECTEM AR $)^{79}$. Por último, el propio Código Sanitario contiene normas a este respecto ${ }^{80}$.

73 El paréntesis es nuestro. Así, entre otras leyes aparte de la 16.744 o el propio Código del Trabajo encontramos al artículo 67 y siguientes del Código Sanitario. A esto cabe agregar una gran cantidad de leyes y reglamentos especiales, tales como la ley 20.001 que regula el peso máximo de carga humana o los decretos respectivos en áreas de seguridad como el decreto $n^{\circ} 133$ del M inisterio del Interior que contiene el reglamento sobre autorizaciones para instalaciones radiactivas 0 equipos generadores de radiaciones ionizantes, personal que se desempeñe en ellas u opere tales equipos y otras actividades afines, de 22 de mayo de 1984, entre muchos otros.

74 "Conviene tener presente que las competencias de la SU SESO, producto del traspaso del control del sistema de pensiones a la Superintendencia de Pensiones, se concentran principalmente en el régimen de Cajas de Compensación de Asignación Familiar, régimen de licencias médicas, algunas prestaciones de (sic) social y el seguro de Accidentes del Trabajo. Por último debe considerarse que el estatuto orgánico de la SU SESO está contenido en la ley № 16.395, del año 1966, es decir, incluso anterior a la ley N N 16.744". Cifuentes (2011) p. 22.

75 Art. 65, Ley N 016.744 y D S 40 de 1969 del M inisterio del Trabajo (en adelante M IN TRAB).

${ }^{76}$ Art. 1 y 28 del D S No 54 de 1969, M IN TRAB.

77 Artículo 2, No 8 del DL 3.525 de 1980. A ello cabe agregar que el artículo 2 del DS 72 de 1986, del M inisterio de M inería, modificado por el DS 14 de 1992, del mismo M inisterio, que aprobó el Reglamento de Seguridad M inera, establece que sus disposiciones son aplicables, "en lo concerniente a prevención de riesgos, a todas las actividades desarrolladas en la industria extractiva minera".

78 Para estos efectos es el Laboratorio Nacional y de Referencia en el campo de la salud ocupacional y contaminación ambiental. (Art. 35 del D L 2.763 de 1979).

79 D ebe velar por el cumplimiento de las medidas de seguridad de las naves en los puertos de la República y de las faenas marítimas, fluviales y lacustre (D FL 292 de 1953 y D L 2222 de 1978).

${ }^{80}$ El libro III del Código Sanitario comprende la normativa referida a La H igiene y Salud del Ambiente y de los Lugares de Trabajo. En los artículos 67 a 93, se encuentra subdividido en cuatro títulos, los cuales refieren a las normas generales; la higiene y seguridad del ambiente, tanto en lo que respecta al agua y sus usos sanitarios (artícul os 69 a 76) como en lo relativo a la vivienda, locales, campamentos y demás (artículos 77 a 81); la higiene y seguridad en los lugares de trabajo (artículos 82 a 88); y otros factores de riesgo, tales como la contaminación del aire, de los ruidos y de las vibraciones (artículo 89) y las sustancias tóxicas o peligrosas para la salud (artículos 90 a 93). 
Esta superabundancia de fiscalización corresponde solucionarla de acuerdo al artículo 191 del Código del Trabajo ${ }^{81}$. Si uno de los servicios facultados para fiscalizar la aplicación de estas normas de higiene y seguridad se constituye en la empresa, los demás servicios deberán abstenerse de intervenir respecto de las materias que están siendo fiscalizadas, en tanto no se haya dado total término al respectivo procedimiento ${ }^{82}$.

Cabe recordar que la infracción administrativa en materia de seguridad en el trabajo debiera surgir con independencia de que se hayan causado daños al trabajador a diferencia de lo que ocurre con la que deriva de la responsabilidad una vez producido el daño. Esta diferencia estriba en que las relaciones jurídicas propias de la administración, debe haber intervención del Estado como institución garantizadora de su existencia83.

Finalmente, el inciso $4^{\circ}$ del nuevo artículo 183 B del Código del Trabajo señala que "El trabajador, al entablar la demanda en contra de su empleador directo, podrá hacerlo en contra de todos aquellos que puedan responder de sus derechos"84. Esto determina ciertas situaciones sobre el problema de la competencia en estas materias, así, si el trabajador del contratista o subcontratista demanda exclusivamente a la empresa principal, debería accionar fuera de la competencia propia de los juzgados del trabajo. Lo debatiremos en otra oportunidad.

\section{CONCLUSIONES}

El incumplimiento de una obligación de seguridad que no acarree daños, simple mente, no dará lugar a indemnizaciones de perjuicios en un juicio de responsabilidad. No hay daño que indemnizar. La obligación de responder no es el resultado de la existencia de una obligación de seguridad en el trabajo a secas, sino que tiene lugar ex novo, por el hecho del incumplimiento del tal obligación que causa daño al trabajador subcontratado.

El empresario principal, el contratista o subcontratista, según sea el caso, están obligados por ley a conocer y dar a conocer las reglas de seguridad que rodean la actividad del trabajador y a aplicarlas, asumiéndose el criterio de que quien lleva adelante una empresa que compromete en su actividad obligaciones de seguridad, se presume iuris et de iure, que conoce las reglas de seguridad que rigen tal actividad. Al fin y al cabo, es un profesional de su actividad.

La naturaleza contractual del derecho de los trabajadores subcontratados a la seguridad y salud en el trabajo no resulta incompatible con el hecho de que el deber de seguridad impuesto legislativamente al empresario principal haya sido configurado al mismo

${ }^{81}$ Lizama et al. (2009), p. 58.

82 Sobre esta fiscalización: Albornoz et al. (2008), pp.159 y siguientes. Sobre estos puntos, Prado (2009) pp. 103 y siguientes.

${ }^{83}$ Así se ha hecho notar en el derecho comparado, por todos, Barbieri, Francesco et al. (2004).

${ }^{84} \mathrm{Q}$ uedará para otro momento analizar si las acciones indemnizatorias tienen un plazo de 5 años de acuerdo al artículo 79 de la Ley № 16.744 de 1968, interpretación que podría ser diferente si damos preeminencia al artículo 2515 del Código Civil, esto es tres años para las acciones ejecutivas o cinco para las ordinarias. Sobre estas materias, Diez (2008) p. 175. 
tiempo como un deber cuyo cumplimiento está orientado a la satisfacción de un interés general y público.

El plan de prevención general de seguridad en régimen de subcontratación no se agotará con su diseño, fue concebido para estar permanentemente en revisión. En ello resulta prioritario evaluar las capacidades profesionales de los trabajadores en materia de seguridad y salud que se desempeñarán en las faenas.

El examen de previsibilidad del empresario principal en relación al hecho, tiene un juicio previo que consiste en la existencia u omisión de las medidas de seguridad, y especialmente de control, de las conductas de riesgo o hechos que pueden acarrear daños. La previsibilidad del daño, en cambio, se genera después, cuando el deber de conducta no se ha materializado en la prevención de las consecuencias del accidente y se causa un perjuicio a causa de un accidente. Las consecuencias desde el punto de vista del juicio de responsabilidad son diferentes. Si no hay previsibilidad del hecho, se determinará la culpa como factor de atribución del responsable. Si no hay previsibilidad del daño, ello determinará la cuantía de la indemnización.

El trabajador en materia de prevención de riesgos laborales debe someterse a la dirección, mando y potestad del empleador que es su contratista. No posee libertad en este punto. La infracción administrativa en materia de seguridad en el trabajo debiera surgir con independencia de que se hayan causado daños al trabajador a diferencia de lo que ocurre con la que deriva de la responsabilidad una vez producido el daño.

\section{BIBLIOGRAFÍA CITADA}

Albornoz Serrano, Marcelo; Alviz Riffo, Cristián; Pérez Mendoza, Enrique (2008): "Subcontratación laboral y servicios transitorios" (Santiago de Chile, LegalPublishing), $405 \mathrm{pp}$.

Alonso, Mariano (2010): "Prólogo" al libro de Llamas Pombo, Eugenio (2010): "Reflexiones sobre D erechos de daños: casos y opiniones" (M adrid, Editorial La Ley) 424 $\mathrm{pp}$.

Áluarez de la Rosa, M . (1997): "El deber de protección y los servicios de prevención de riesgos laborales", AAVV (Casas Bahamonde, M. E., Palomeque López, M. C. y ValdÉs DaL-Ré, F. Coords.), "Seguridad y salud en el trabajo. El nuevo D erecho de la prevención de riesgos profesionales" (M adrid, La Ley-Actualidad) p. 58.

Arenas de Mesa, Alberto (1999): "Proyecciones del déficit previsional chileno: gasto público en pensiones asistenciales 1999-2010". Disponible en http://docs.google.com/ viewer?a=v\& q=cache:H U qyk-kJU dU J :www.eclac.org/publicaciones/xml/4/7284/lcl1456e_VIb. pdf +gasto+en +siniestralidad +en +chile+en +relaci $\%$ C 3\% B3n+a+PI B \& $h l=e s \& g l=c l \& p i d=b l$ \& srcid=AD GEEShtU j-5L8li3K E 9vlumA4Z OW JN EAiw99bkbcW U ddbxQ 0 5EnnH nuG bc KT L 9IAB5W Bi297IEd15tXD XxBB20BAvD x7KO jeXpQ 8H RnKM F8aY8IU_C KD Q R3Wyr C rCH ST E 2xjM 7AV s9N \& sig=AH IEtbR 37U O jM pw9uM D W noC SaeggiM C nrw (fecha de consulta 21 de julio de 2011).

Asociación CHILENa de SEguridad (2008) "Reportes" p. 59. Disponible en http://ww3. achs.cl/ws/wps/wcm/connect/ece6a3804fbe8c95af1bef080f4d3a2b/BIRE_RS06.pdf?M O D =AJ 
PERES\& CACH EID =ece6a3804fbe8c95af1bef080f4d3a2b (fecha de consulta 18 de octubre de 2011).

Asúa González, Clara (2008): "Pérdida de oportunidad en la responsabilidad sanitaria", Cuadernos de Aranzadi Civil, núm. 31/2008, BIB 2008\579.

Baraona González, Jorge (2011): "La Culpa de la víctima en los accidentes del trabajo: D ogmática y jurisprudencia chilenas" en Rodríguez Pinto, M aría Sara y Barrientos Camus, Francisca (Coordinadoras): Cuadernos de extensión jurídica (U niversidad de los Andes) $N^{\circ} 20$, pp. 147-182.

Barbieri, M arco; M acario, Francesco y Trisorio, Giuseppe (2004): "La tutela in forma specifica dei diritti nel rapporto di lavoro" (M ilano, Giuffré) 439 pp.

Barros Bourie, Enrique (2006): "La diferencia entre "estar obligado" y "ser responsable" en el derecho de los contratos", en Corral Talciani, Hernán y Rodríguez Pinto, M aría Sara (Coordinadores): Estudios de Derecho Civil II (Santiago, LexisN exis) pp. 721-752.

Caprile Biermann, Bruno, (2011): “El Iucro cesante por muerte o incapacidad del trabajador en la jurisprudencia; aspectos relevantes" en Rodríguez Pinto, M aría Sara y Barrientos Camus, Francisca (Coordinadoras): Cuadernos de extensión jurídica (U niversidad de los Andes) $N^{\circ} 20$, pp. 103-146.

Cifuentes Lillo, H ugo (2011): “Los Riesgos del Trabajo y su Prevención: camino a una reforma" en Revista Laboral Chilena, abril 2011, pp. 13-29.

Carrancho Herrero, María Teresa (2010): "Responsabilidad civil del empresario en el ámbito de los riesgos laborales" (M adrid, La Ley) 388 pp.

Corral Talciani, Hernán (2010): "Concurrencia de acciones de responsabilidad civil contractual y extracontractual en los daños causados por accidentes del trabajo. Cuadernos de extensión jurídica" en Rodríguez Pinto, M aría Sara y Barrientos Camus, Francisca (Coordinadoras): Cuadernos de extensión jurídica (U niversidad de los Andes) $\mathrm{N}^{\circ} 20$, pp. 49-82.

Deutsch, E. (1966): “Begrenzung der $\mathrm{H}$ aftung aus abstrakter Gefahrdung wegen fehlender adáquater Kausalitát?", JZ 1966/17, 556 vd. [JZ 1966], pp. 558-559.

Díez-Picazo, Luis (1980): “La Responsabilidad Civil H oy”, en A.D .C. (M adrid), pp. 723-737.

Díez Schwerter, José Luis (2008): "Responsabilidad Civil derivada de accidentes del trabajo y enfermedades profesionales: Aspectos relevantes de su regulación y operatoria actual en Revista de Derecho de la Pontificia Universidad Católica de Valparaíso (Valparaíso, Chile, $2^{\circ}$ semestre de 2008) pp. 163-185.

Domínguez Águila, Ramón (1994) "Comentarios de Jurisprudencia. Daño moral en la responsabilidad contractual. Ausencia de norma excluyente de su reparación". en Revista de Derecho (Universidad de Concepción) $N^{\circ} 196$, año LXII, julio-diciembre 1994, pp. 155-160.

(1993) "Comentarios de Jurisprudencia. Responsabilidad de Derecho común. Responsabilidad legal. Reglas aplicables". en Revista de Derecho (Universidad de Concepción) N 193 LXI, enero-junio, 1993, pp. 163 y 164. 
(1993) "Comentarios de Jurisprudencia. Responsabilidad contractual. Daño M oral. Cúmulo de responsabilidades. Prueba del daño moral". en Revista de Derecho (U niversidad de Concepción) N 193 año LXI, enero-junio, 1993, pp. 160-163.

(1996) "El hecho de la víctima como causal de exoneración de responsabilidad civil". en Revista de Derecho (Universidad de Concepción) $N^{\circ} 136$ año XXIV abril-junio, 1966, pp. 29-54.

(2011): "Los accidentes del trabajo. Historia y visión general de su régimen actual". en Rodríguez Pinto, M aría Sara y Barrientos Camus, Francisca (Coordinadoras): Cuadernos de extensi ón jurídica (U niversidad de los Andes) N²0, pp. 21-35.

Fernández Marcos, Leodegario (1995): "D erecho de seguridad e higiene en el trabajo" (M adrid, Edifap), 283 pp.

Gamillscheg, F., Hanau, P. (1965): “Die H aftung des Arbeitsnehmers", en Verlag Versicherungswirtschaft e. V., Karlsruhe, 1965, p. 37.

Gamonal Contreras, Sergio; Guidi Moggia, Caterina (2010) "M anual de Contrato de Trabajo" (Santiago de C hile, Abedelo Perrot) 329 pp.

GonzÁlez LABRADA, M anuel (1996): "Seguridad y salud en el trabajo y responsabilidad contractual del empresario" (Barcelona, C edecs) 602 pp.

Gumucio Rivas, Juan Sebastián (1999) "Responsabilidad Subsidiaria: notas sobre el artículo 64 del Código del Trabajo" en Revista laboral Chilena, agosto de 1999, pp. 59 y ss.

(2000) "M odificaciones al régimen de responsabilidad subsidiaria por obligaciones de contratistas y subcontratistas (ley 19.666)" en Revista Iaboral Chilena, abril de 2000, pp. 91-93.

Gumucio Rivas, Juan Sebastián, Susacasa Massone, Javier (2011) "Examen de los regímenes de responsabilidad de la empresa principal en los siniestros profesionales sufridos por trabajadores de empresas contratistas y subcontratistas" en Revista Laboral Chilena, abril 2011, pp. 81 a 86.

Gutiérrez-Solar Calvo, Beatriz (2004): "Culpa y riesgo en la responsabilidad civil por accidentes de trabajo" (M adrid, T homson-Civitas), 345 pp.

Huber, U . (1973): "Verschulden, G efáhrdung und Adáquanz", en "Festschrift für E. Wahl" (H eidelberg, Cari Winter U niversitátsverlag), pp. 309-310.

Humeres Noguer, H éctor (2009): "D erecho del Trabajo y de la Seguridad Social", Tomo I, D ecimoctava edición (Santiago de Chile, Editorial Jurídica de C hile) 510 pp.

Jordano Fraga, F. (1987): "La responsabilidad contractual" (M adrid, Civitas). 512 pp.

LaI, M arco (2010): "D iritto della salute e della sicurezza sul lavoro". (Roma, Giappichelli) pp. X-274.

Lamarca I Marqués, A. (2002) "Entra en vigor la ley de modernización del derecho alemán de obligaciones", InD ret (www.indret.com), 1/2002. (Fecha de consulta: 24 de julio de 2011).

Larenz, Karl (1985): "D erecho Justo, Fundamentos de ética jurídica” (M adrid, Civitas) 120 $\mathrm{pp}$.

Lizama Portal, Luis y Ugarte Cataldo, José Luis (2009): "Subcontratación y suministro de trabajadores" (Santiago, LegalPublishing), cuarta edición, 191 pp. 
Luque Parra, M . (2002): "La responsabilidad civil del empresario en materia de seguridad y salud laboral" (M adrid, C onsejo Económico y Social) 223 pp.

Martín Hernández, M aría Luisa (2006): "El derecho de los trabajadores a la seguridad y salud en el trabajo" (M adrid, Consejo Económico y Social) 408 pp.

Mazeaud, Henry, Mazeaud León, Mazeaud Jean (1959): "L ecciones de D erecho civil", parte segunda, volumen I (Buenos Aires, Ed. Jurídicas Europa- América) 410 pp.

Melis Valencia, Cristián y Sáez Carlier, Felipe (2009): "El contrato individual de trabajo en los dictámenes de la Dirección del Trabajo" (Santiago de Chile, Editorial LegalPublishing) 633 pp.

Montoya Melgar, Alfredo (2004): "Panorama de la responsabilidad del empresario en materia de seguridad y salud en el trabajo" en Revista del M inisterio de Trabajo y Asuntos Sociales, 2004, 53, pp. 307-319.

Montuschi, L. (1989): "D iritto alia salute e organizzazione del lavoro", 3a ed. (M ilano, Franco Angelí), 1989, p. 383.

(2006) "La Corte. Costituzionale e gli standard di sicurezza del lavoro" en ADL, 2006, n. 1, 3. Moraga Neira, René (2009): "Código del Trabajo comentado" Tomo I (Santiago de C hile, LegalPublishing) 555 pp.

Natullo, G . (1995) "La tutela dell ambiente di lavoro" (Torino, U tet), 210 pp.

Peña, Carlos y Pizarro, Carlos (2004): "Informe en derecho sobre responsabilidad subsidiaria del dueño de la obra”, en Revista Chilena de D erecho Privado, N o 2 (2004) pp. 152-162.

Prado, Pamela (2009) "La subcontratación y el suministro en el derecho civil" (Santiago, LegalPublishing) 117 pp.

Ramos Quintana, Margarita Isabel (2007): "Subcontratación de obras o servicios y transmisión empresarial" (Albacete, España, Editorial Bomarzo) 131 pp.

Reglero, Francisco (2002): "Lecciones de Responsabilidad Civil" (M adrid, ThomsonAranzadi, Cizur M enor), 1a edición (octubre de 2002) p. 535.

(2008) "Tratado de responsabilidad civil" Autores: Luis Fernando Reglero Campos (coord.) Editores: Cizur-M enor: Thomson-Aranzadi, 2008 Edición: 4ạ España, 1475 $\mathrm{pp}$.

Rodríguez Pinto, M aría Sara (2011): “Las tendencias en daño moral por muerte o lesión corporal de un trabajador en la jurisprudencia civil y laboral". en Rodríguez Pinto, M aría Sara y Barrientos Camus, Francisca (C oordinadoras): Cuadernos de extensión jurídica (U niversidad de los Andes) N²0, pp.83-102.

Santoni, F., (1979): "La posizione soggettiva del lavoratore dipendente" (Napoli, Casa editrice D ott. Eugenio J ovene) 388 pp.

Schiele Manzur, Carolina (2011): "Sentencia que acoge el criterio de la no solidaridad del dueño de la obra, empresa o faena", en Revista Chilena de Derecho de Seguros, año 13, número 20, Santiago, mayo de 2011, pp. 37-58.

Sierra Herrero, Alfredo (2011): "La responsabilidad del empleador por enfermedades profesionales de sus trabajadores. Enfoque jurisprudencial", en Rodríguez Pinto, M aría Sara y Barrientos Camus, Francisca (C oordinadoras): Cuadernos de extensión jurídica (U niversidad de los Andes) N²0, pp. 37 a 47. 
Simi, V. (1969): “Interesse pubblico e attivitá amministrativa nella tutela della sicurezza del lavoro", en Rivista Giuridica per la Industria, núm. 1, 1969, pp. 4 y 6. Smuraglia, La sicurezza del lavoro e la sua tutela pénale, 2a ed., M ilano, 1967, p. 58.

Ugarte Cataldo, José Luis (2006), "Sobre relaciones laborales triangulares: La subcontratación y el suministro de trabajadores" en Revista lus et praxis. N 12, 2006, pp. 11-29.

Ugarte, José Luis y Lizama, Luis (2007), "Subcontratación y suministro de trabajadores" (Santiago de Chile, LexisN exis) pp. 167.

Vargas Viancos, María Carolina (2011): "Seguridad y Salud en la M inería” en Revista Laboral Chilena, abril 2011, pp. 66-74.

Walker E., Francisco (2003): “D erecho de las Relaciones Laborales", Editorial U niversitaria, 2003, p. 720.

Zelaya Etchegaray, Pedro (2004): "La responsabilidad subsidiaria del dueño de obra, empresa o faena por los daños causados al trabajador del contratista o subcontratista". en Revista de D erecho y Jurisprudencia. Tomo Cl, vol 2, año 2004, pp. 25-64.

(2006) "La responsabilidad solidaria de la empresa principal frente a los daños experimentados por los trabajadores del contratista" en Revista de Derecho y jurisprudencia, tomo CIII, N 0 1, Santiago 2006, pp. 1-29.

(2003) "La responsabilidad subsidiaria del dueño de la obra, empresa o faena por los daños causados al trabajador del contratista o subcontratista" en Revista de Derecho y J urisprudencia, Tomo CI No 2, Santiago 2003, pp. 43-44.

Yzquierdo Tolsada, M ariano (1993): Responsabilidad civil contractual y extracontractual. Volumen I (M adrid, ed. Reus) 253 pp.

\section{NORMAS CITADAS}

Constitución Política de la República.

Código Civil Chileno.

Código del Trabajo.

Ley 16.744, Establece normas sobre accidentes del trabajo y enfermedades profesionales. 1 de febrero 1968.

$B G B$

Dictamen 2468-053 de la Dirección del Trabajo.

Dictamen 1696-024 de la Dirección del Trabajo.

D ecreto Supremo 76, del M inisterio del Trabajo y Previsión social. Aprueba reglamento para la aplicación del art. 66 bis de la ley 16.744 sobre la gestión de la seguridad y salud en el trabajo en obras, faenas o servicios que indica. 14 de diciembre de 2006.

O rd. $\mathrm{N} 0$ 141/05 de la Dirección del Trabajo.

O rd. $\mathrm{N}$ 2.468/053 de la D irección del Trabajo.

O rd. $\mathrm{N} \cong$ 4.881/103 de la D irección del Trabajo.

Código Sanitario.

DFL 292 de 1953

D L 2222 de 1978. 
DL 2.763 de 1979.

DL 3.525 de 1980.

DS 72 de 1986, del M inisterio de M inería, modificado por el DS 14 de 1992

Art. 1 y 28 del D S No 54 de 1969, del M inisterio del Trabajo

DS 40 de 1969 del M inisterio del Trabajo.

D ecreto $\mathrm{N}^{\circ} 133$, de 22 de mayo de 1984 del Ministerio del Trabajo.

Reglamento sanitario sobre manejo de residuos peligrosos $N^{\circ} 148$ de 12 de junio de 2003, del M inisterio de Salud.

Ley 20.001 que regula el peso máximo de carga humana.

O rden de Servicio N 8. de 05.04.2007, D irección del Trabajo.

\section{JURISPRUDENCIA CITADA}

Díaz Díaz, Enrique con Erazo Vidal Jorge (2009): Corte Suprema. 22 de abril de 2009. Rol 7339-2009

Elgueta Collante, Roberto M. con Servicios Industriales y Forestales Larraín Ltda. y otra. Corte de apelaciones de Concepción. 26 de octubre de 2010. Rol 156-2010

Fuentes Castro, Patricio con Codelco Chile y otra. Corte Suprema. 4 de mayo de 2011. Rol 759-2009.

González Corrotea, Julio con M arineer Zona Franca S.A. y otra. Corte de Apelaciones de Antofagasta. 31 de julio de 2010, Rol 08-2010.

Martínez Pérez, David c/ Sociedad Inmobiliaria e Inversiones Hormazábal M iranda Ltda. Corte de Apelaciones de Rancagua, 4 de febrero de 2010, Rol 83-2009.

Navarro Jerez, M oisés con Sociedad Forestal y Comercial Araucaria Ltda. y otros. Corte de Apelaciones de Concepción. 12 de noviembre de 2009, Rol 363-2009.

Puerto de Lirquén S.A. con Fisco de Chile. Corte de Apelaciones de Concepción 23 de julio de 2010, Rol 2097-2010.

Ramos Alvarado, Rodrigo R. c/ Asegi m Ltda. y otra. Corte de Apelaciones de La Serena, 7 de diciembre de 2010, Rol 130-2010.

Saavedra Guajardo, I gnacio con Carnes Ñ uble S.A. y otra. Corte de Apelaciones de C hillán, 2 de marzo de 2011, Rol 68-2010.

Salgado Solar, Rosendo con Sociedad Prestadora de Servicios M edio Ambiente Preserva Ltda. e Ilustre Municipalidad de Talcahuano. Corte de Apelaciones de Concepción, 12 de noviembre de 2010, Rol 56-2010.

Germán Silva Valencia con S Y R Tecnología y Servicios Integrales. Corte de Apelaciones de Santiago, 20 de julio de 2010, Rol 8755-2009.

O rellana Pavez, Cristián M. con Confortaire Ingeniería y Servicios Ltda. Corte de Apelaciones de Santiago, 30 de junio de 2010, Rol 9755-2009. 
